\title{
Applicability of literature values for Green-Ampt parameters to account for infiltration in hydrodynamic rainfall-runoff simulations in ungauged basins
}

Franziska Tügel ( $\nabla$ franziska.tuegel@wahyd.tu-berlin.de )

Technische Universität Berlin https://orcid.org/0000-0002-8878-5521

Aziz Hassan

Technische Universität Berlin: Technische Universitat Berlin

Jingming Hou

Xi'an University of Technology

Reinhard Hinkelmann

Technische Universität Berlin: Technische Universitat Berlin

\section{Research Article}

Keywords: robust 2D shallow water model, hydrodynamic rainfall-runoff modeling, Hydroinformatics Modeling System, ungauged catchments, automatic calibration

Posted Date: March 2nd, 2021

DOI: https://doi.org/10.21203/rs.3.rs-237260/v1

License: (c) (i) This work is licensed under a Creative Commons Attribution 4.0 International License. Read Full License

Version of Record: A version of this preprint was published at Environmental Modeling \& Assessment on August 16th, 2021. See the published version at https://doi.org/10.1007/s10666-021-09788-0. 


\title{
Applicability of literature values for Green-Ampt parameters to account for infiltration in hydrodynamic rainfall-runoff simulations in ungauged basins
}

\author{
Franziska Tügel*1 ${ }^{\star 1}$ Aziz Hassan ${ }^{1}$, Jingming Hou² \& Reinhard Hinkelmann \\ ${ }^{1}$ Technische Universität Berlin, Chair of Water Resources Management and Modeling of Hydrosystems, Straße \\ des 17. Juni 135, 10623 Berlin, Germany \\ ${ }^{2}$ Xi'an University of Technology, School of Water Resources and Hydro-Power Engineering, China \\ *corresponding author: franziska.tuegel@wahyd.tu-berlin.de, ORCID: 0000-0002-8878-5521
}

\begin{abstract}
This study aims to evaluate the suitability of literature parameter values for the Green-Ampt infiltration model to be used in hydrodynamic rainfall-runoff simulations. The outcome of this study supports to decide which literature values should be taken if observed data for model calibration is not available. Different laboratory experiments, a plot-scale experiment in the Thiès catchment in Senegal, and flash floods in the region of El Gouna in Egypt have been simulated with the 2D shallow water model Hydroinformatics Modeling System (hms) incorporating the Green-Ampt model. For four test cases with available runoff data, the results of the calibrated models were compared to those obtained from average values after Rawls et al. [54] and Innovyze [27]. The results showed a clear underestimation of infiltration in two of three considered laboratory experiments, while for a field experiment in Senegal, average values after Rawls et al. [54] led to a strong overestimation and the ones after Innovyze [27] to an underestimation of infiltration. In a case study on flash floods in an ungauged region in Egypt, the values of both sources led to a strong overestimation of infiltration, when the simulation results are compared to observed flooding areas. It can be concluded, that the values after Innovyze [27] lead to overall better results than the ones after Rawls et al. [54]. According to the results, the hydraulic conductivity in ungauged areas with bare sandy soil should be reduced by about 90 - $100 \%$ compared to the value after Rawls et al. [54].
\end{abstract}

\section{Keywords}

robust 2D shallow water model, hydrodynamic rainfall-runoff modeling, Hydroinformatics Modeling System, ungauged catchments, automatic calibration 


\section{Introduction}

Hydrodynamic models are more and more used to simulate not only the flow and flooding areas of surface waters but also rainfall-induced overland flow in small catchments $[6,34,43,63,75]$, the propagation of flash floods $[1$, $5,26,69]$, and flood inundation in urban areas $[9,32,59,80]$. Due to the enhanced accuracy and resolution of topographic data, the interest in using $2 \mathrm{D}$ hydrodynamic models is continuously increasing, and since different techniques of high-performance computing are developed to accelerate numerical computations, the powerful potential of shallow water models can be realized more and more and be used also in practical applications [33, 48].

Additionally, to the calculation of the flow field, appropriate methods to represent the runoff generation are needed to establish an integrated hydrological-hydrodynamic model. As $2 \mathrm{D}$ shallow water models are typically used for the simulation of relatively short flooding events of some hours up to a few days rather than long-term rainfall-runoff simulations, infiltration represents the most important water loss [17], while evapotranspiration can be neglected in many cases or taken into account in a very simplified way. Infiltration describes the process when rainwater or ponding water is absorbed by the soil. The infiltrated water can either flow further downstream in the unsaturated zone relatively close and parallel to the surface (interflow), be stored in the unsaturated soil zone, or percolate into deeper soil layers and finally contribute to groundwater recharge. For flood modeling it is specifically interesting how much water of the rainfall will lead to overland runoff and how much is "lost" by infiltration. The infiltration process is influenced by many factors, such as soil texture class, soil moisture, soil surface condition, soil bulk density, content of organic matters and litter in the soil, land cover, land use, topography, rainfall characteristics as well as spatial variability of soil properties $[3,25,42,47,58]$. It has been for example observed, that infiltration capacities are usually higher on vegetated than on bare soil surfaces, which is caused for example by the protection of the surface against the kinetic energy of raindrops preventing the rearrangement of soil particles and thus surface sealing or crust formation. Steeper slopes generally lead to faster runoff and therefore lower infiltration rates then on plane surfaces [47]. Conversely, Ribolzi et al. [57] showed in their study about field experiments on steep slopes with a texture class of clay loam, that microterraces tend to form on a slope of $75 \%$, and are significantly more pervious than the ripple-like roughness that occurred on a gentler slope of $30 \%$. Furthermore, their observations confirmed the hypothesis that higher effective rainfall intensity was responsible for the formation of less permeable erosion crusts on the $30 \%$ slope than the structural crusts that developed on the $75 \%$ slope. Mohammadzadeh-Habili and Heidarpour [40] carried out column experiments and numerical simulations to study various effects of infiltration into layered soils. If, for 
example, water infiltrates through an upper layer of finer and less permeable soil than the coarser sublayer, the wetting front usually considered as stable becomes unstable forming narrow wetting columns or fingers. Assouline and Mualem [3] concluded from their study on heterogeneous small bare catchments, that the impact of surface sealing is much more important than the one of spatial soil variability. Ries et al. [58] conducted 120 experiments with a rainfall simulator on different land covers and soil types with different initial water contents, rain intensities and durations. Based on their observations they stated, that simplified approaches, which are still often applied in models used for the risk management of flash floods - up to the strongest simplification of completely neglecting the runoff reduction during heavy rainfalls - are not suitable. This is shown beyond others by the fact, that in their conducted experiments even saturated soils still showed significant infiltration rates [58].

Especially for rural areas and green urban infrastructure, the infiltration losses have to be taken into account. A good understanding of infiltration and its representation in models is crucial not only for the appropriate risk management of heavy rainfalls and flash floods but also for successful solutions of water harvesting and groundwater recharge [3]. Concerning the global trends of ongoing urbanization and climate change coming along with more frequent and more intense hydro-meteorological extremes in terms of floods and droughts, damages from inundations on the one hand and lowered groundwater tables and water stress, on the other hand, will increase and get more severe in future [26, 30, 34, 39]. To mitigate these effects, so-called water-sensitive or climate-adapted urban planning and water resources management strategies considering sustainable urban drainage systems (SUDS) $[20,74]$ and low impact developments (LIDs) $[13,31,50]$ are gaining increasing importance. Measures such as infiltration basins and trenches, raingardens, or permeable pavement should lead back to a more natural water cycle to mitigate flood risks, store water, and stabilize groundwater tables. To investigate the effectiveness of such sustainable stormwater management measures an appropriate representation of infiltration in 2D hydrodynamic rainfall-runoff models is also needed

There exist many different approaches to model the water losses caused by infiltration, starting from simplified empirical approaches such as the well-known runoff-coefficient, loss-rate, and SCS-CN (Soil Conservation Service Curve Number) methods as well as the Horton equation, more physically-based methods like the Philip infiltration model and the Green-Ampt model, up to the Richards equation. In investigations of Caviedes-Voullième et al. [6], the SCS-CN method was found to be inadequate to be coupled with a distributed model for runoff computations, and as the Richards equation is very complex and the solution needs a lot of computational effort as well as many measured data $[16,71]$, simplified equations are often used in rainfall-runoff models, where the Green-Ampt model is one of the most popular ones [7, 17, 34, 55]. Developed by Green and Ampt already in 1911 [21], many different applications, modifications, and extensions have been carried out in 
the last more than 100 years, and in many test cases it was proven that this model is generally able to appropriately represent infiltration processes [17, 38, 48, 73]. The fractured-order Green-Ampt (FOGA) model as introduced e.g. in Fernández-Pato et al. [18] results in a generalized formulation of the Green-Ampt model. The ability to better fit observed runoff curves of complex rainfall events could be significantly improved by the FOGA model.

The main problem for real-world applications consists in estimating the Green-Ampt parameters, namely the hydraulic conductivity, capillary suction head at the wetted front, and effective porosity (representing the saturated soil water content), additionally to the initial soil water content of the soil. For simple test cases or laboratory experiments, these parameters might be measured directly, but due to the high effort and costs, it is usually not feasible to directly measure the needed soil properties at enough locations within large areas as it would be needed for real-world applications $[60,67]$. If available runoff and sometimes even infiltration time series exist, the Green-Ampt parameters can be considered as calibration parameters [17, 48 ; Simons et al 2014). As also observed runoff data is often not available for real-world applications, e.g. considering flash floods or ungauged catchments, the Green-Ampt parameters have to be estimated based on relations to more easily available soil properties such as the soil texture class. Many different of such methods have been developed over the past decades. The probably best known and most cited contribution is the study of Rawls et al. [54], where they developed a table of parameter sets in dependence on soil texture class and soil horizon. These average parameter values are the result of analyzing 5000 soil horizons in the USA, for which the Green-Ampt parameters were derived from the Brooks and Corey parameters that were fitted before to the available water retention data. For a more accurate estimation than taking those average values for the given soil texture class and if more detailed soil information is available, they recommend predicting the water retention matrix potential curve by a regression equation based on particle size distribution, organic matter, bulk density, and 0.33 bar and 15 bar moisture retention values. The best option, of course, would be to determine the Green-Ampt parameters based on measured water retention matrix potential data [54], but as mentioned before this is usually too costly and too much effort for large areas in real-world applications. Other typical values for the Green-Ampt parameters are for example recommended in the manual of the modeling software company Innovyze [27], referring to different sources, such as Akan [2]. Furthermore, there have been several studies on finding suitable regression equations, where the Green-Ampt parameters can be derived from more easily measured parameters such as percentages of clay, sand, gravel, and the bulk density [79], or from the percentage of surface cover and crusting or initial soil moisture and antecedent rainfall [72]. 
Especially, on bare soils with no vegetation, the kinetic energy of raindrops can disturb and rearrange soil aggregates resulting in the formation of a surface crust or sealing $[41,44,45]$. Such layers can lead to a significant decrease in the infiltration capacity by 20 to 2000 times [37,61]. The thickness of such layer has been reported to vary from 1 to $5 \mathrm{~mm}[61,65]$. Different adaptions and extensions of infiltration models to account for the effects of a surface crust have been developed $[3,4]$. A very simple one is a modified Green-Ampt model, where the hydraulic conductivity is calculated as effective hydraulic conductivity of the crust and subcrust soil [4, $14,45,56]$. Another important factor that can influence infiltration processes is the microtopography, which was for example investigated by Esteves et al. [14], Fiedler and Ramirez [19], Mallari et al. [36], Thompson et al. [68], and Xiang et al. [79]. Also, friction can influence infiltration, as higher friction leads to lower flow velocities and more water can infiltrate during the decelerated propagation of the flood wave.

For practical applications, tabulated standard parameters depending on the soil texture class as represented by Rawls et al. [54] or Innovyze [27] are very interesting and might sometimes be assumed without further knowledge about the actual infiltration behavior, especially when investigating ungauged areas. As it is not clear whether these literature values represent a good assumption of the actual infiltration in larger-scale rainfall-runoff simulations, further analysis is desirable. This study aims to analyze the applicability of tabulated values from two different literature sources to consider infiltration with the Green-Ampt model in 2D shallow water models. Recommendations should be given for rainfall-runoff simulations in ungauged areas in terms of in which cases the tabulated values of which source are suitable to estimate infiltration or giving tendencies how to adapt them. After describing the applied methods, the characteristics and setups of different test cases with measured data are represented. For each test case, the results of several simulations with different parameter sets are presented to evaluate the performance of the model when taking into account the average parameter values compared to the calibrated ones. Three of the test cases are laboratory experiments and one is a field experiment on a small plot in the Thiès catchment in Senegal, where also the extension for crusted soils is exemplarily taken into account to evaluate its effect. Finally, a case study on flash floods in an ungauged desert region in Egypt is shown and the plausibility of the results based on the average values for the Green-Ampt parameters and the impact of a surface crust and friction on infiltration is analyzed. 


\section{Material \& Methods}

\section{$2.12 D$ shallow water model for overland flow}

The Hydroinformatics Modelling Sytem (hms) is used to simulate the flow field in terms of flow velocities and water depths. It is a Java-based flexible and extendable modeling framework, which has been developed at the Chair of Water Resources Management and Modeling of Hydrosystems of the Technische Universität Berlin, Germany. Previous studies using hms have been carried out for example by Hassan et al. [23], Özgen et al. [49], Simons [62], and Tügel et al. [69]. In hms, the depth-averaged 2D shallow water equations are solved with an explicit cell-centered finite volume method, and incorporates robust numerical methods such as the HLLC Riemann solver and a sophisticated total variation diminishing method (TVD) to deal with the numerical challenges, which are associated for example with the simulation of very small water depths over complex topography or the propagating wet-dry fronts [63]. The general form of the 2D conversation law can be expressed as follows:

$$
\frac{\partial \mathbf{q}}{\partial \mathrm{t}}+\frac{\partial \mathbf{f}}{\partial \mathrm{x}}+\frac{\partial \mathbf{g}}{\partial \mathrm{y}}=\mathbf{s}
$$

where $\mathbf{q}$ is the vector of conserved state variables, $t$ is the time, $\mathbf{f}$ and $\mathbf{g}$ denote the vectors of advective and diffusive fluxes in $\mathbf{x}$ - and $y$-direction, respectively and the vector $\mathbf{s}$ represents the source terms. This equation describes mathematically, that a temporal change of the conserved variables in the control volume can only be caused by a net flux over the surface of the control volume and/or by sinks/sources within the control volume. Inserting the following vectors in the general conservation law (Equation 1) yields in the shallow water equations (Equation 2):

$$
\begin{gathered}
\boldsymbol{q}=\left[\begin{array}{c}
\mathrm{h} \\
\mathrm{uh} \\
\mathrm{vh}
\end{array}\right], \quad \mathbf{f}=\left[\begin{array}{c}
\mathrm{uuh}+\frac{1}{2} \mathrm{gh}^{2}-\mathrm{v}_{\mathrm{t}} \nabla(\mathrm{uh}) \\
\mathrm{uvh}
\end{array}\right] \\
\mathbf{g}=\left[\begin{array}{c}
\mathrm{vh} \\
\mathrm{vuh} \\
\mathrm{vvh}+\frac{1}{2} \mathrm{gh}^{2}-\mathrm{v}_{\mathrm{t}} \nabla(\mathrm{vh})
\end{array}\right], \mathbf{s}=\left[\begin{array}{c}
\mathrm{r} \\
-\mathrm{gh} \frac{\partial \mathrm{z}_{\mathrm{B}}}{\partial \mathrm{x}}-\mathrm{f}_{\mathrm{x}} \\
-\mathrm{gh} \frac{\partial \mathrm{z}_{\mathrm{B}}}{\partial \mathrm{y}}-\mathrm{f}_{\mathrm{y}}
\end{array}\right] \text { (2) }
\end{gathered}
$$

Here, the first row of each vector contains the mass balance equation and the second and third rows represent the momentum balance equations in $\mathrm{x}$ - and $\mathrm{y}$-direction, respectively. $\mathrm{h}$ is the water depth, $\mathrm{u}$ and $\mathrm{v}$ are the velocity vector components in $\mathrm{x}$ - and $\mathrm{y}$-direction, respectively, and $\mathrm{z}_{\mathrm{B}}$ is the bottom elevation above datum. uh and vh represent the specific discharge in $x$ - and $y$-direction, respectively. $r$ is a mass source/sink term accounting for 
precipitation, infiltration or injection/abstraction of water, $g$ denotes the gravitational acceleration, $v_{t}$ the turbulent viscosity, and $\rho$ the density of water. The external forces $f_{x}$ and $f_{y}$ include the bottom friction. In this study, the turbulent viscosity $\mathrm{v}_{\mathrm{t}}$ is set to zero and other external forces except the friction are not considered. The wellknown friction law after Manning was used for test cases 2 and 3 as well as for the case study about flash floods in El Gouna:

$$
u=\frac{1}{n} h^{2 / 3} \sqrt{S}
$$

where $\mathrm{n}$ denotes Manning's friction coefficient, and $\mathrm{S}$ the friction slope. In the test case 4 , the depth-dependent Manning's coefficient after Jain et al. [28] was used, as Mügler et al. [43] showed that the application results in the best representation of the velocity field for the considered area:

$$
n(h)= \begin{cases}n_{0}\left(\frac{h}{h_{o}}\right)^{-\varepsilon} & \text { for } h<h_{0} \\ n_{0} & \text { for } h \geq h_{0}\end{cases}
$$

Where $\mathrm{n}$ denotes the depth-dependent Manning's friction coefficient, no the minimum land surface-dependent Manning's friction coefficient corresponding to flow depth $\mathrm{h}_{0}$ beyond which $\mathrm{n}$ is assumed to be constant, and $\varepsilon$ is a parameter accounting for drag due to vegetation. As laminar flow conditions were proven in the laboratory experiment after Smith and Woolhiser [64], the laminar friction law as described in Smith and Woohlhiser (1971) and Delfs et al. [10], was used in the first test case:

$$
u=C_{\text {laminar }} S H^{2}
$$

\subsection{Green-Ampt model for infiltration}

In the Green-Ampt model, the cumulative infiltration and the infiltration rate are calculated with the following equations:

$$
\begin{gathered}
F(t)=K t+\left(h_{0}-h_{f}\right) \Delta \theta \ln \left(1+\frac{F(t)}{\left(h_{0}-h_{f}\right) \Delta \theta}\right) \\
f(t)=K\left(1+\frac{\left(h_{0}-h_{f}\right) \Delta \theta}{F(t)}\right)=\frac{d F}{d t}(7)
\end{gathered}
$$

where $F(t)$ denotes the cumulative depth of infiltration, $f(t)$ the infiltration rate, $K$ the hydraulic conductivity at residual air saturation; according to Whisler \& Bouwer [78], $\mathrm{K}$ is assumed to be $50 \%$ of the saturated hydraulic conductivity $\mathrm{K}_{\mathrm{s}} . \mathrm{h}_{\mathrm{f}}$ is the wetted front capillary suction head, and $\mathrm{h}_{\mathrm{o}}$ is the ponding water depth. $\Delta \theta$ denotes the soil moisture deficit, which is the difference between the saturated soil water content $\theta_{\mathrm{s}}$, usually considered with 
the effective porosity $n_{\text {eff, }}$ and the initial moisture content $\theta_{i}$. The wetted front capillary suction head, effective porosity, and hydraulic conductivity are called Green-Ampt parameters.

When the considered soil tends to generate a surface crust of lower hydraulic conductivity, Brakensiek and Rawls [4] proposed to calculate the effective hydraulic conductivity of a two-layer soil - crust and subcrust by a harmonic mean [56]:

$$
K_{e}= \begin{cases}K_{e} & \text { for } Z_{f} \leq Z_{c} \\ \frac{Z_{f}}{\frac{z_{f}-Z_{c}}{K}+\frac{Z_{c}}{K_{c}}} & \text { for } Z_{f}>Z_{c}\end{cases}
$$

where $\mathrm{K}_{\mathrm{e}}$ is the effective hydraulic conductivity, $\mathrm{K}_{\mathrm{c}}$ is the hydraulic conductivity of the crust, $\mathrm{Z}_{\mathrm{c}}$ is the crust thickness, and $Z_{f}$ denotes the wetted depth which is calculated by the cumulative infiltration depth from the previous timestep divided by the soil moisture deficit.

\subsection{Literature values of Green-Ampt parameters}

2.4 Rawls et al. [54] analyzed different soils and determined average Green-Ampt parameters based on soil texture classes, where five of them are shown in Table 1.

Table 1 Average values and ranges of the Green-Ampt parameters after Rawls et al. [54]

\begin{tabular}{cccc}
\hline Soil texture class & $\begin{array}{c}\text { Effective porosity } \\
\mathbf{n}_{\text {eff }}(-)\end{array}$ & $\begin{array}{c}\text { Capillary suction at } \\
\text { wetted front } \mathbf{h}_{\mathbf{f}} \\
(\mathbf{c m})\end{array}$ & $\begin{array}{c}\text { Hydraulic conductivity } \\
\mathbf{K}(\mathbf{c m} / \mathbf{h})\end{array}$ \\
\hline Sand & $0.417(0.354-0.480)^{*}$ & $4.95(0.97-25.36)^{* *}$ & 11.78 \\
Loamy sand & $0.401(0.329-0.473)$ & $6.13(1.35-27.94)$ & 2.99 \\
Loam & $0.434(0.334-0.534)$ & $8.89(1.33-59.38)$ & 0.34 \\
Clay loam & $0.309(0.279-0.501)$ & $20.88(4.79-91.10)$ & 0.10 \\
Clay & $0.385(0.269-0.501)$ & $31.63(6.39-156.5)$ & 0.03 \\
\hline
\end{tabular}

*Numbers in parentheses: one standard deviation around the average

${ }^{* *}$ Antilog of the log mean and standard deviation

Other values are for example given in the help documentation of the hydraulic and hydrologic modeling software XPStorm and XPSWMM of the Innovyze company [27]. They refer to typical values for the minimum (asymptotic) infiltration rate corresponding to the saturated hydraulic conductivity for different soil texture classes after Akan [2], typical values for the average capillary suction head from several published values, as well as typical values for the initial soil moisture deficit at wilting point. The authors state that these values for the initial soil moisture deficit would apply for very dry conditions, and lower values should be used when wetter initial conditions occur. The values for five different soil texture classes are given in Table 2. When comparing these values with the ones 
after Rawls et al. [54], it is striking that for sand the maximum value for the hydraulic conductivity after Akan [2] is about one order of magnitude lower, and roughly halved for loamy sand, but approximately doubled for loam, while the minimum value for loam after Akan [2] is very similar to the one after Rawls et al. [54]. For clay loam the maximum value after Akan [2] is very similar to that after Rawls et al. [54], and for clay the value after Rawls et al. [54] is closer to the minimum value after Akan [2]. The average capillary suction head after Akan [2] is higher than after Rawls et al. [54] for all soil types except for clay.

Table 2 Typical values of Green-Ampt paramters given in Innovyze [27]

\begin{tabular}{cccc}
\hline Parameter & $\begin{array}{c}\text { Typical initial moisture } \\
\text { deficit at wilting point }\end{array}$ & $\mathbf{h}_{\mathbf{f}}(\mathbf{c m})$ & $\mathbf{K}(\mathbf{c m} / \mathbf{h})$ \\
\hline Reference & Clapp and Hornberger [8] & several sources & Akan [2] \\
\hline Sand & 0.34 & 10.16 & $0.76-1.14$ \\
Loamy sand & - & - & $0.76-1.14$ \\
Loam & 0.31 & 20.32 & $0.38-0.76$ \\
Clay loam & 0.24 & 25.40 & $0.00-0.13$ \\
Clay & 0.21 & 17.78 & $0.00-0.13$ \\
\hline
\end{tabular}

\subsection{Optimization techniques}

Especially, if several parameters need to be calibrated, automatic calibration is required as a manual calibration would be very time-consuming, because many simulations have to be carried out varying all calibration parameters sequentially, and possible dependencies between several parameters have to be considered as well. Automatic calibration makes use of an optimization algorithm, to find the optimum parameter combination as fast as possible. Several simulations with varying parameter values are carried out automatically, where the ranges for each parameter can be defined by the user. To carry out an automatic calibration of the Green-Ampt parameters and in some cases also initial water content and the friction within predefined ranges, optimization techniques that are implemented in the SciPy package optimization were used in this study. For the results presented in this work, the Simplicial homology global optimization (SHGO) algorithm was used [11]. Within this algorithm, the global minimum of a chosen objective function is searched by varying the different calibration parameters within predefined reasonable ranges. The well-known Nash-Sutcliffe efficiency [46] as well as the non-parametric Kling-Gupta efficiency [52], which are both included in the PyPI package hydroeval [24], were used as objective functions:

$$
N S E=1-\frac{\sum\left(Q_{s i m}-Q_{o b s}\right)^{2}}{\sum\left(Q_{o b s, \text { mean }}-Q_{o b s}\right)^{2}}
$$


where NSE denotes the Nash-Sutcliffe efficiency, $Q_{\text {sim }}$ and $Q_{\text {obs }}$ are the simulated and observered discharge values at different times respectively, and $Q_{\text {obs, mean }}$ is the mean value of the observed values.

$$
K G E_{n p}=1-\sqrt{(\beta-1)^{2}+\left(\alpha_{n p}-1\right)^{2}+\left(r_{s}-1\right)^{2}}
$$

$K_{G E}$ is the non-parametric Kling-Gupta efficiency, $\beta$ denotes the bias between simulated and observed mean discharge calculated as simulated mean divided by observed mean, $\alpha_{n p}$ is the non-parametric form of the discharge variability, and $r_{s}$ the non-parametric correlation term, calculated with the Spearman rank correlation on the ranks of the observed and simulated discharge time series. For both indicators - NSE and KGE of one would express a perfect fit of simulated to observed discharges. Within the optimization algorithm, the calibration parameters are varied to reach the minimum of the combined error from NSE and KGE

$$
\text { error }=(1-N S E)+\left(1-K G E_{n p}\right)
$$

\subsection{Experimental setups and study areas}

Four different test cases with available data for calibration and one case study about flash floods in the ungauged area of El Gouna, Egypt are investigated. The basic information on each case is summarized in Table 3 and the experimental setups (Test $1-4$ ) and study area characteristics (Case study El Gouna) are briefly described in the following sections.

\begin{tabular}{|c|c|c|c|c|c|c|}
\hline Case & Source & Type & $\begin{array}{l}\text { Texture } \\
\text { class }\end{array}$ & $\begin{array}{l}\text { Extensions } \\
\quad(\mathrm{m})\end{array}$ & $\begin{array}{l}\text { Slope } \\
(\%)\end{array}$ & Rainfall data \\
\hline Test 1 & $\begin{array}{c}\text { Smith and } \\
\text { Woolhiser [64] }\end{array}$ & $\begin{array}{c}\text { Lab } \\
\text { experiment }\end{array}$ & Fine sand & $12.200 \times 0.051$ & 1 & $\begin{array}{c}4.2 \mathrm{~mm} / \mathrm{min} \\
15 \mathrm{~min}\end{array}$ \\
\hline Test 2 & Lima [35] & $\begin{array}{c}\text { Lab } \\
\text { experiment }\end{array}$ & Loam & $1.0 \times 0.5$ & 10 & $\begin{array}{c}2.25 \mathrm{~mm} / \mathrm{min} \\
15 \mathrm{~min}\end{array}$ \\
\hline Test 3 & Lima [35] & $\begin{array}{c}\text { Lab } \\
\text { experiment }\end{array}$ & Clay loam & $1.0 \times 0.5$ & 10 & $\begin{array}{c}2.25 \mathrm{~mm} / \mathrm{min} \\
15 \mathrm{~min}\end{array}$ \\
\hline Test 4 & Tatard et al. [66] & $\begin{array}{l}\text { Field test in } \\
\text { Senegal }\end{array}$ & Sand & $10 \times 4$ & 1 & $\begin{array}{l}\text { Time series } \\
86 \mathrm{~min}\end{array}$ \\
\hline $\begin{array}{l}\text { Case } \\
\text { study }\end{array}$ & Tügel et al. [69] & $\begin{array}{l}\text { Flash flood } \\
\text { simulations El } \\
\text { Gouna, Egypt }\end{array}$ & Sand & $\begin{array}{l}9000 x \\
11000\end{array}$ & 0.5 & $\begin{array}{c}\text { Time series } \\
10.3 \text { hours }\end{array}$ \\
\hline
\end{tabular}

Table 3 Overview of studied test cases

\subsubsection{Test case 1 - Laboratory experiment after Smith and Woolhiser [64]}

As a first test case, the well-known rainfall-runoff experiment of Smith and Woolhiser [64] was chosen. They equipped a laboratory-scale soil flume of $12.2 \mathrm{~m}$ length, $0.051 \mathrm{~m}$ width, $1.22 \mathrm{~m}$ depth with river-deposit sand 
(Poudre fine sand) and porous flume ends to collect the seepage water to get a prototype infiltrating slope (Fig. 1). To create artificial rainfall, they installed drop-producing manifolds, and to prevent splash erosion, the soil surface was covered with gauze. In the considered experiments, the adjustable slope was set to $1 \%$. The runoff was measured continuously by a pressure transducer and to observe the moving soil moisture front, gamma-ray attenuation was used. The soil properties were experimentally determined. Through comparison of the observed surface runoff hydrograph and simulations with their coupled model of the one-dimensional Richards equation for infiltration and the kinematic-wave model for overland flow (solved with the finite-difference method), they figured out that the observed data were fitted well when a laminar friction law was taken into account in the model (see Equation 5).

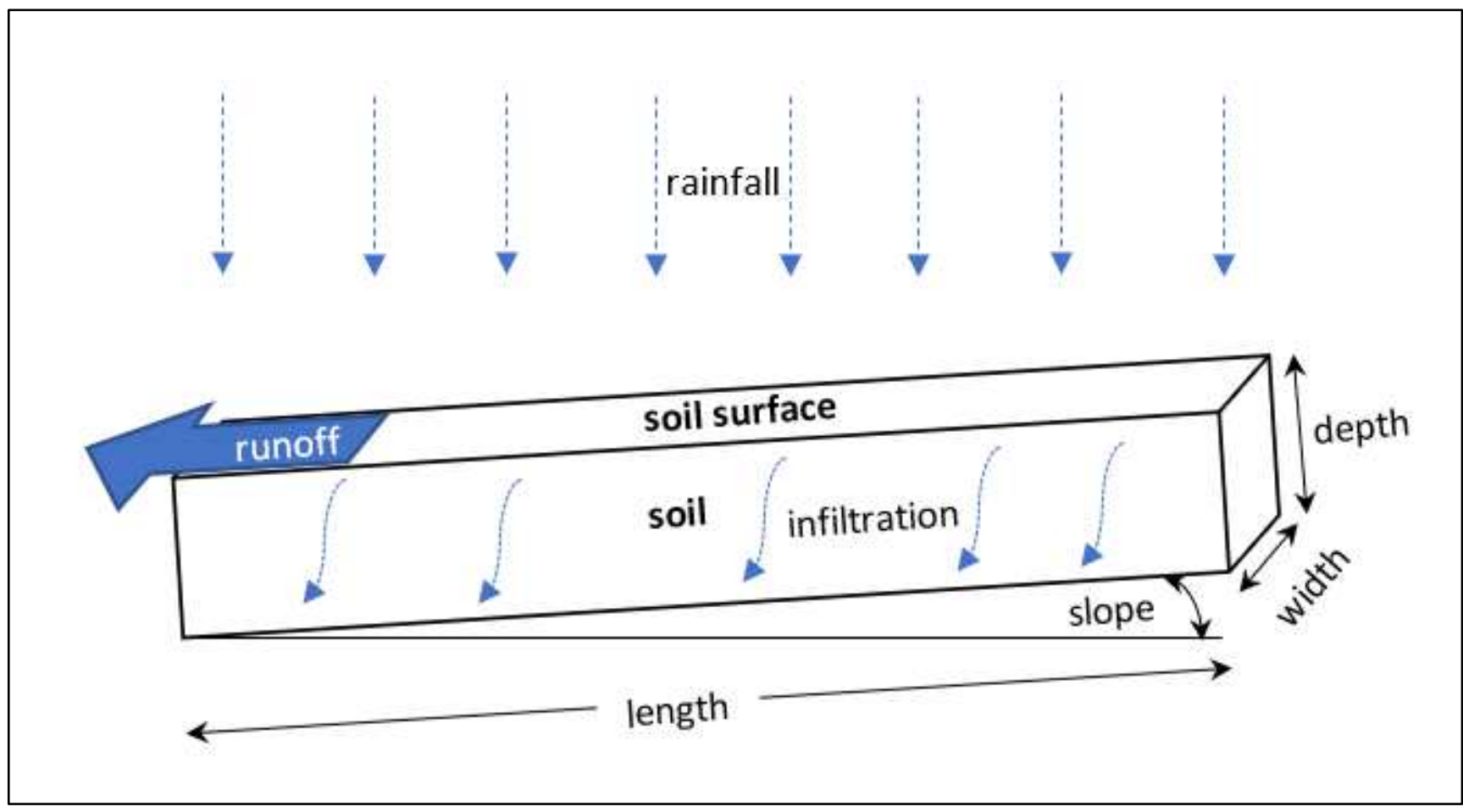

Fig. 1 Sketch of soil flume of the laboratory experiments in Test cases 1, 2 and 3

\subsubsection{Test cases 2 and 3 - Laboratory experiments after Lima [35]}

As the second and third test cases, two laboratory experiments after Lima [35] were chosen. A soil flume according to Fig. 1 of $1 \mathrm{~m}$ length, 0.5 width, $0.08 \mathrm{~m}$ depth, a slope of $10 \%$, and with percolated metal plates at the bottom to collect the percolation water was used together with a programmable rainfall simulator to carry out rainfall-runoff experiments with different soils. The first soil was a loam collected from Limburg in the Netherlands (Test 2) and the second soil was a clay loam collected from Alentejo in Portugal (Test 3). The initial and saturated soil water contents as well as the average particle densities and average soil bulk densities were measured by Lima, other parameters such as the hydraulic conductivities were estimated. 


\subsubsection{Test case 4 - Field experiment in Thiès catchment, Senegal [66]}

The field experiment on a plot of $10 \mathrm{~m} \times 4 \mathrm{~m}$ within the Thiès catchment in Senegal (14 $45^{\prime} 43^{\prime \prime} \mathrm{N}, 16^{\circ} 53^{\prime} 16^{\prime \prime} \mathrm{W}$ ) was considered as the last test case (Fig. 2). The details of the experimental setup are presented in Tatard et al. [66], and Mügler et al. [43], while Simons et al. [63] already presented previous simulations with hms and the Green-Ampt model. The plot consisted of sandy soil and the average slope was approximately $1-1.5 \%$. Different rainfall-runoff tests have been carried out by using a rainfall-simulator.
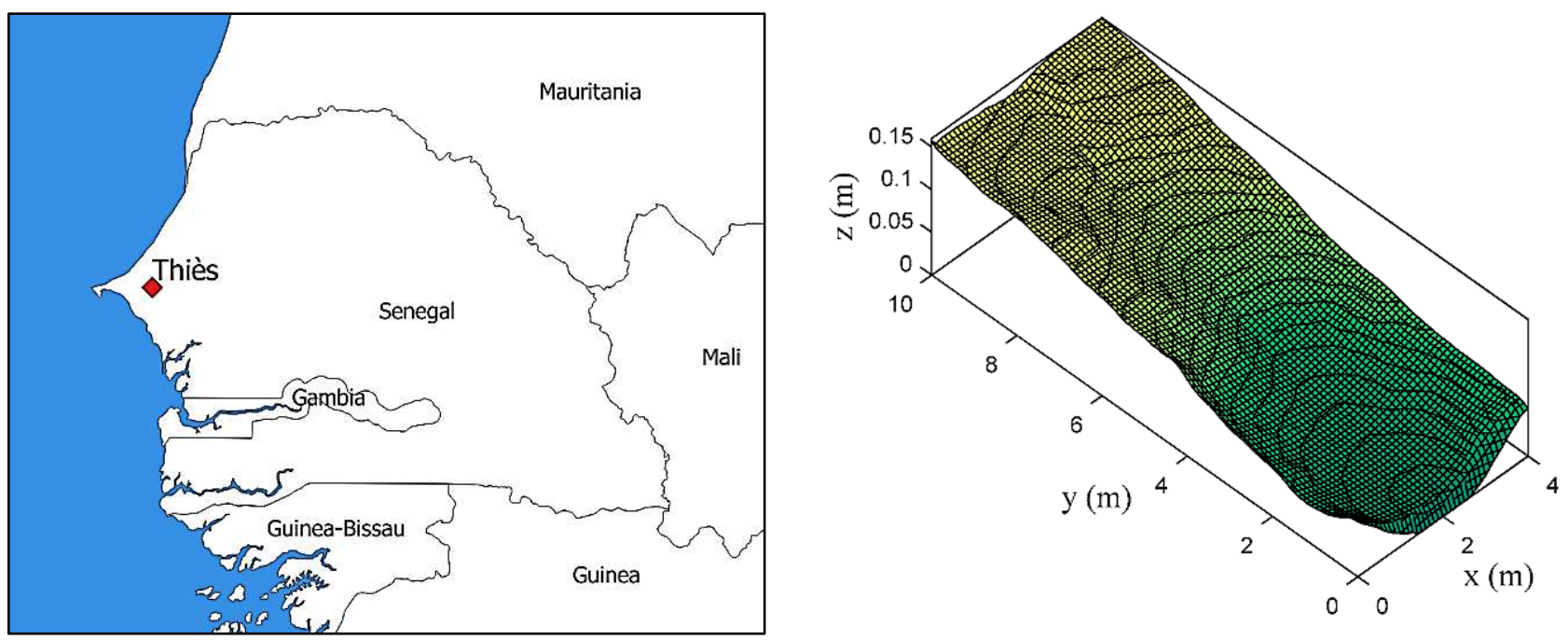

Fig. 2 Left: Location of the Thiès catchment in Senegal (made with Natural Earth), right: elevation of the tested basin [51]

\subsubsection{Case study - Flash flood simulations in El Gouna, Egypt}

El Gouna is a touristic town in the Eastern Desert of Egypt. Although the climate is extremely dry, from time to time strong rainfall events especially in the mountainous areas can generate fast and devastating flash floods, as the usually dry wadi systems turn into rivers with very fast flows. Many settlements, infrastructure, and cities have been constructed inside those usually dry wadi catchments. During flash flood events, these areas are strongly affected and the flooding can cause severe damages to the environment, infrastructure, and properties, and in the worst-case endanger human lives. Consequently, the areas have to face economic, ecological, and social problems due to flash floods. El Gouna is located on the coastal plain inside the delta of the usually dry Wadi Bili. In case of a flood, some streams reach El Gouna, and others drain into the Red Sea north of El Gouna. Heavy rainfall that generates flash floods in the region of El Gouna occurs sporadically in the winter half-year between October - April and often comes from the direction of the Red Sea. Several flash floods and resulting infrastructure damages have been reported in the recent years, e.g. in December 2010, March 2014, October 2015, and October 2016, where total rainfall amounts of approximately 7, 34, 10, and $20 \mathrm{~mm}$, respectively, have been observed by satellite data (for the event in 2010) or recorded by the weather station in El Gouna (for events 
in 2014, 2015, and 2016) [77]. As a very exceptional occasion, manual discontinuous velocity measurements and corresponding discharge estimations could have been carried out during the flash flood event in March 2014, and are published in Hadidi [22]. Fig. 3 represents the location of El Gouna in Egypt, the topography, catchment boundary and streams of Wadi Bili until the point where the velocity measurements have been carried out in 2014, and the detail of the model domain of El Gouna between the measurement point in the Wadi Bili catchment and the Red Sea.

\subsection{Procedure and numerical model setups}

For the four test cases with available data for calibration (Table 3), simulations with different parameter sets are carried out:

- With average values for the Green-Ampt parameters for the given soil after Rawls et al. [54] (see Table 1 for parameter values) to check the performance if these values would be taken without calibration in case of ungauged areas.

- With optimum parameters values as result of the automatic calibration, where the ranges are set for the given soil type after Rawls et al. [54] according to Table 1, and/or within larger ranges (for example the

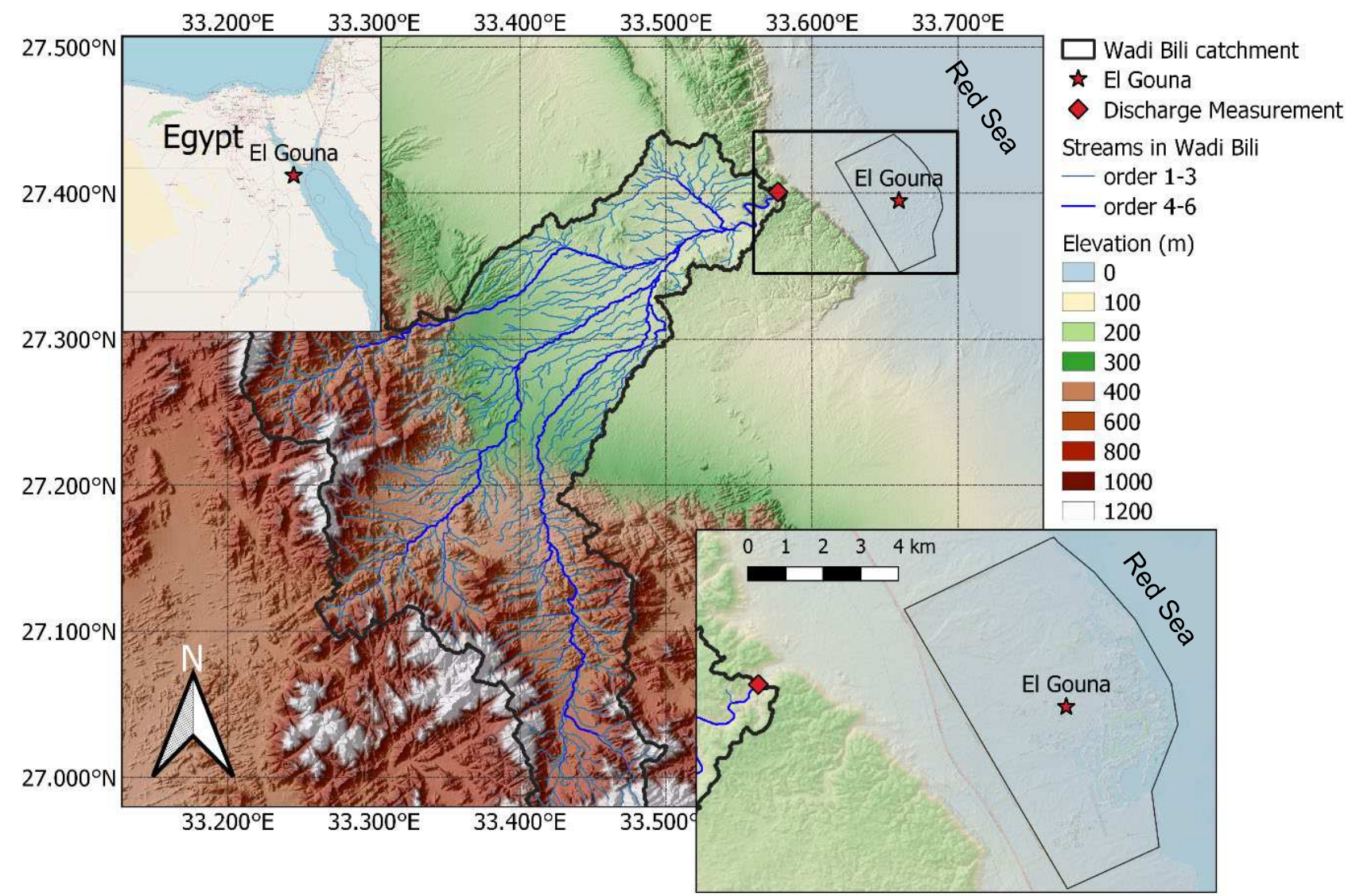

Fig. 3 Location of El Gouna and the Wadi Bili catchment in Egypt, topography (AW3D30 @ Jaxa), and streams in the Wadi Bili catchment and model domain for the area of El Gouna as well as the location of discharge measurements in 2014 published in Hadidi [22] (map: @OOpenStreetMap contributors) 
combined ranges of two consecutive soil types) to reach the best fit between model and observations within reasonable ranges.

- If available: with parameters values that were derived from direct measurements or calibration given in the literature corresponding to the experiments to check the performance when only the remaining unknown parameters are calibrated.

- With typical values for the Green-Ampt parameters after the help documentation from Innovyze [27] (see Table 2) to check their performance if these values would be taken without calibration in case of ungauged areas.

- In Test 4: exemplarily considering a thin surface crust of lower hydraulic conductivity with the approach of a harmonic mean as given in Section 2.2, as infiltration with the parameters after Rawls strongly overestimate infiltration and as surface sealing may occur on bare soils during heavy rainfalls.

The runoff hydrographs from different parameter sets are evaluated through comparison to the observed ones. Additionally, a case study with flash flood simulations in Egypt is represented under consideration of different values for the infiltration and friction parameters, analyzing the plausibility of the results and the effect of friction and surface crusts on infiltration processes. Table 4 gives an overview of the model setups and the overall ranges for friction and Green-Ampt parameters covering all ranges of different optimization and simulation runs for each case. The subsequent sections briefly describe the setup of each case. 


\begin{tabular}{|c|c|c|c|c|c|c|c|}
\hline \multirow{2}{*}{ Case } & \multirow{2}{*}{$\begin{array}{l}\text { Cell size } \\
(\mathrm{m} \times \mathrm{m})\end{array}$} & \multirow{2}{*}{$\begin{array}{l}\text { Simulation } \\
\text { time }\end{array}$} & \multirow{2}{*}{$\begin{array}{l}\text { Friction } \\
\text { law }\end{array}$} & \multicolumn{4}{|c|}{$\begin{array}{l}\text { Overall ranges for friction and GA parameters* } \\
\text { (varied in different optimization/simulation cases) }\end{array}$} \\
\hline & & & & Friction & $\begin{array}{c}\Delta \theta \\
\left(\mathrm{m}^{3} / \mathrm{m}^{3}\right)\end{array}$ & $\begin{array}{c}\mathrm{K} \\
(\mathrm{m} / \mathrm{s})\end{array}$ & $\begin{array}{l}\mathrm{h}_{\mathrm{f}} \\
(\mathrm{m})\end{array}$ \\
\hline Test 1 & $\begin{array}{l}0.01 x \\
0.01\end{array}$ & $17 \mathrm{~min}$ & $\begin{array}{l}\text { Claminar } \\
\left(\mathrm{m}^{-1} \mathrm{~s}^{-1}\right) \\
\text { Eq. } 5\end{array}$ & $\begin{array}{l}1.3 \mathrm{E}+06- \\
1.4 \mathrm{E}+06\end{array}$ & $\begin{array}{l}0.203- \\
0.480\end{array}$ & $\begin{array}{l}8.3 \mathrm{E}-06 \\
3.3 \mathrm{E}-05\end{array}$ & $\begin{array}{l}0.0097 \\
0.2794\end{array}$ \\
\hline Test 2 & $\begin{array}{l}0.05 x \\
0.05\end{array}$ & $17 \mathrm{~min}$ & $\begin{array}{c}\text { Manning } \\
\left(\mathrm{sm}^{-1 / 3}\right) \\
\text { Eq. } 3\end{array}$ & $0.010-0.033$ & $\begin{array}{l}0.310- \\
0.523\end{array}$ & $\begin{array}{l}9.5 \mathrm{E}-07 \\
2.1 \mathrm{E}-06\end{array}$ & $\begin{array}{l}0.0133 \\
0.5938\end{array}$ \\
\hline Test 3 & $\begin{array}{l}0.05 x \\
0.05\end{array}$ & $17 \mathrm{~min}$ & $\begin{array}{l}\text { Manning } \\
\left(\mathrm{sm}^{-1 / 3}\right) \\
\text { Eq. } 3\end{array}$ & $0.012-0.033$ & $\begin{array}{l}0.204- \\
0.495\end{array}$ & $\begin{array}{l}1.1 \mathrm{E}-07 \\
3.6 \mathrm{E}-07\end{array}$ & $\begin{array}{l}0.0479 \\
0.9110\end{array}$ \\
\hline \multirow{2}{*}{ Test 4} & \multirow{2}{*}{$\begin{array}{l}0.10 x \\
0.10\end{array}$} & \multirow{2}{*}{$86 \min$} & \multirow{2}{*}{$\begin{array}{l}\text { Manning } \\
\text { depth- } \\
\text { depend. } \\
\text { Eq. } 4\end{array}$} & \multirow{2}{*}{$\begin{array}{l}\mathrm{n}_{0}: 0.014 \mathrm{sm}^{-1 / 3} \\
\text { ho: } 0.0045 \mathrm{~m} \\
\varepsilon: 0.1\end{array}$} & $\begin{array}{l}0.154- \\
0.480\end{array}$ & $\begin{array}{l}\text { 2.6E-06- } \\
\text { 3.3E-05 }\end{array}$ & $\begin{array}{l}0.0097 \\
0.2536\end{array}$ \\
\hline & & & & & & $\begin{array}{l}\text { Crust: } \\
5 \mathrm{~mm}, \mathrm{~K}_{\mathrm{c}}=\end{array}$ & 1E-06 \\
\hline \multirow{2}{*}{$\begin{array}{l}\text { Case } \\
\text { study }\end{array}$} & \multirow{2}{*}{$\begin{array}{l}15.0 x \\
15.0\end{array}$} & \multirow{2}{*}{$43 \mathrm{~h}$} & \multirow{2}{*}{$\begin{array}{l}\text { Manning } \\
\left(\mathrm{sm}^{-1 / 3}\right) \\
\text { Eq. } 3\end{array}$} & \multirow{2}{*}{$0.01-0.02$} & $\begin{array}{l}0.404- \\
0.387\end{array}$ & $\begin{array}{l}9.4 \mathrm{E}-07 \\
3.3 \mathrm{E}-05\end{array}$ & $\begin{array}{l}0.0495 \\
0.0889\end{array}$ \\
\hline & & & & & $Z_{c}=$ & $\begin{array}{l}\text { Crust: } \\
5 \mathrm{~mm}, \mathrm{~K}_{\mathrm{c}}=\end{array}$ & 3E-08 \\
\hline
\end{tabular}

*based on the ranges given in Rawls et al. [54] and Innovyze [27] (see Section 2.3)

\subsubsection{Test case 1-Laboratory experiment after Smith and Woolhiser [64]}

The domain was discretized in rectangular cells of $1 \mathrm{~cm} \times 1 \mathrm{~cm}$ leading to 6100 cells, and all boundaries were defined as open. Artificial rainfall with a rate of $4.2 \mathrm{~mm} / \mathrm{min}(252 \mathrm{~mm} / \mathrm{h})$ was imposed over 15 minutes, and the total simulation time was set to 17 minutes. The initial conditions for water depths and flow velocities were set to zero. From the initial soil moisture profile measured by Smith and Woolhiser [64], an average initial saturation of $S_{i}=0.2$ can be assumed as the initial condition for the soil, which was transferred here into the initial soil water content by $\theta_{\mathrm{i}}=\mathrm{S}_{\mathrm{i}} \cdot \theta_{\mathrm{s}}$, which therefore depends on the assumed saturated soil water content, namely the effective

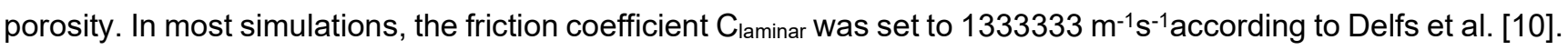

\subsubsection{Test cases 2 and 3-Laboratory experiments after Lima [35]}

The domain was discretized in rectangular cells of $5 \mathrm{~cm} \times 5 \mathrm{~cm}$ leading to 200 cells, and all boundaries were defined as open. In both cases after Lima [35], a constant rainfall of $2.25 \mathrm{~mm} / \mathrm{min}$ (135 mm/h) was imposed for 
15 minutes and the total simulation time was set to 17 minutes. The initial conditions for water depths and flow velocities were set to zero. The initial soil water content was 0.0107 for the loam from Limburg (Test 2), and 0.006 for the clay loam from Alentejo (Test 3), and were not varied during the simulations. In Test 2, Manning's friction coefficient $\mathrm{n}$ was varied between $0.010-0.033 \mathrm{sm}^{-1 / 3}$, representing the range from bare sand to bare clay loam after Engman [12], as there is no value given for loam. In Test 3, Manning's friction coefficient was varied between $0.012-0.033 \mathrm{~s} \cdot \mathrm{m}^{-1 / 3}$ corresponding to the range for bare clay loam after Engman [12].

\subsubsection{Test case 4 - Field experiment in Thiès catchment, Senegal [66]}

The domain was discretized in rectangular cells of $10 \mathrm{~cm} \times 10 \mathrm{~cm}$ leading to 4141 cells. The upstream boundary was set as open, all other boundaries were set as closed according to Simons [62]. The experimental results in terms of measured rainfall and runoff time series of an 86 minutes long experiment, where the average rainfall intensity was $70.76 \mathrm{~mm} / \mathrm{h}$ (see Fig. 11 in Section 3.4), were used for the numerical investigations. The initial conditions for water depths and flow velocities were set to zero. The initial soil water content was varied between zero as calibrated in Simons [62] and 0.2. Manning's friction law with depth-dependent Manning's coefficient as described in Section 2.1 was used with the calibrated parameters from Simons [62]: $\mathrm{n}_{0}=0.014 \mathrm{sm}^{-1 / 3}, \mathrm{~h}_{0}=0.0045$ $\mathrm{m}$ and $\varepsilon=0.1$.

\subsubsection{Case study - Flash flood simulations in El Gouna, Egypt}

The model domain of about $11 \mathrm{~km} \times 8 \mathrm{~km}$ was discretized into 438372 rectangular cells of $15 \mathrm{~m} \times 15 \mathrm{~m}$. The topography is represented by the digital surface model (DSM) ALOSWORLD 3D (AW3D30) with a horizontal resolution of $30 \mathrm{~m}$ [29], which was interpolated to a cell size of $10 \mathrm{~m}$. Buildings were incorporated into the DSM by increasing the elevations inside building polygons extracted from OpenStreetMap (see Fig. 4 in Section 2.5.4). All boundaries were considered open except for $30 \mathrm{~m}$ at the western boundary, where the inflow from the upstream wadi catchment enters the coastal plain. The hydrograph from a hydrological model, which was calibrated with the measured hydrograph by Hadidi [22], was implemented as boundary condition to simulate the flash flood event from 09 March 2014 [70]. Furthermore, a time series of rainfall intensities (Fig. 4) that has been measured at the weather station located at the TU Berlin Campus El Gouna, was imposed as source term in each cell. The accumulated rainfall amount was $34 \mathrm{~mm}$. The initial conditions for water depths and flow velocities were set to zero. The initial soil water content was set to $0.03 \mathrm{~m}^{3} / \mathrm{m}^{3}$ and not varied during the simulation, assuming dry conditions, which represents the typical conditions in the study area. The friction was varied 
between 0.01 and $0.02 \mathrm{sm}^{-1 / 3}$ according to the average values for bare sand and bare clay loam after Engman [12].

As most parts of the model domain consist of natural surfaces, mainly in terms of non-vegetated bare sand, infiltration cannot be neglected. After the Harmonized World Soil Database [15] as well as from field investigations, which were carried out within a student research project at TU Berlin Campus El Gouna, the dominant soil type in that area is sand (Fig. 5). Although no measurements are available for model calibration, former studies showed that taking into account the average Green-Ampt parameters for sand after Rawls et al. [54] leads to a strong overestimation of infiltration, as the entire rainfall inside the domain and almost the whole incoming flood wave from the large wadi catchment completely infiltrated before reaching the city of El Gouna [69]. As there have been large flooding areas observed by the population - reported in personal conversations with shop owners and staff members of the desalination plant as well as reported through photographs of inundation areas and resulting damages - it is obvious, that the infiltration is not represented realistically. In addition to the overestimation of infiltration due to the assumed Green-Ampt parameters, also spatial rainfall patterns, which are not taken into account as the rainfall data of only one weather station was available, could also contribute to this wrong representation. Especially bare soils in arid areas are lacking vegetation cover, and have therefore no protection from raindrop impact, which might lead to soil crusting going along with a large reduction of the infiltration capacity [41]. Therefore, the approach of a Green-Ampt model for crusted soils as described in Section 2.2 is taken into account, and the impact of a crust as well as friction is studied. As for sand and loamy sand, almost all water infiltrated very fast, loam was also considered, as this texture class is also occurring in this area according to the Harmonized World Soil Database.

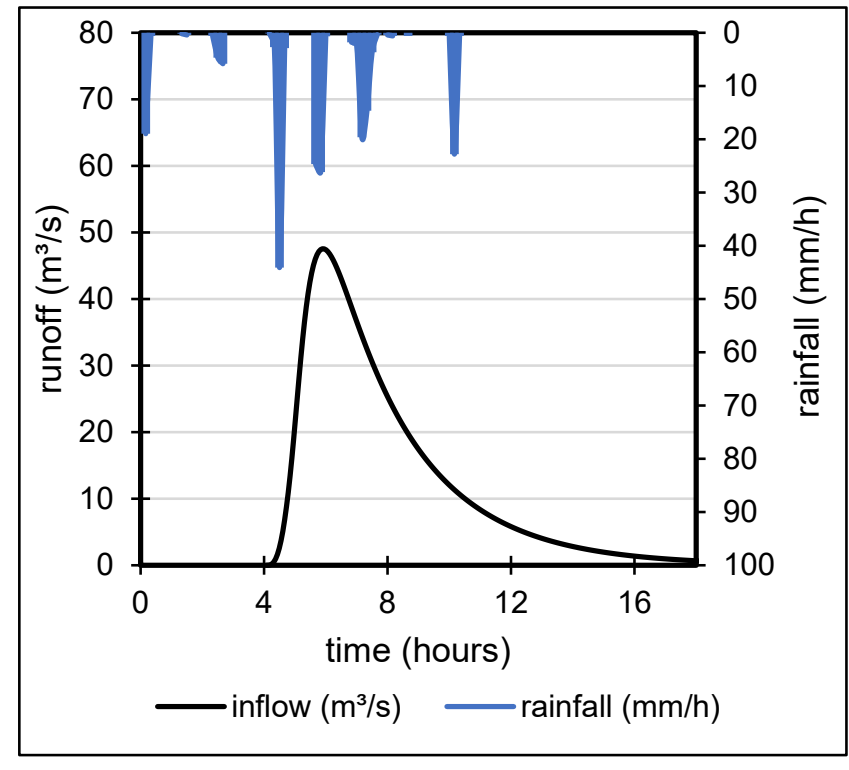

Fig. 4 Rainfall and inflow imposed as source and boundary condition in the model, respectively

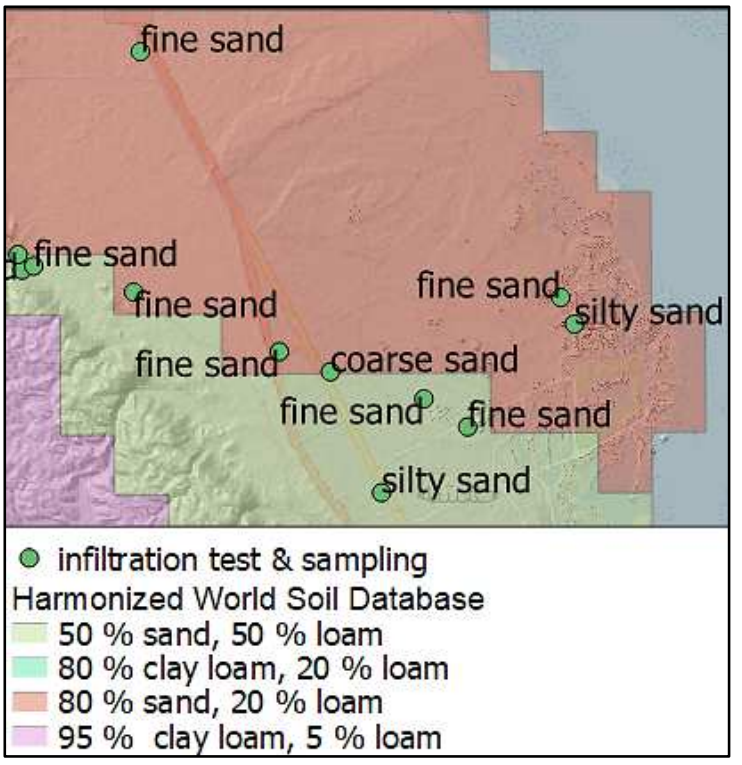

Fig. 5 Soil texture classes according to the Harmonized World Soil Database and determined from double-ring infiltrometer tests 


\section{Results}

\subsection{Test case 1 - Laboratory experiment after Smith and Woolhiser [64]}

The simulated runoff hydrographs for the different parameter sets (as described in Section 2.6) are shown in Figure 6, and the corresponding parameter sets as well as indicators for the goodness-of-fit are summarized in Table 5. When the average Green-Ampt parameters after Rawls et al. [54] for sand are considered in the model, the surface runoff is strongly overestimated for the whole rising limb of the hydrograph, and runoff starts about 180 seconds before the observed runoff. However, the peak discharge is well captured in magnitude and occurs only 9 seconds earlier than the observed one. The NSE for the overall hydrograph is -0.245 , indicating a bad agreement between simulated and observed hydrograph (see Table 5, line 1; green line with circles in Fig. 6). When using the Green-Ampt parameters that resulted from the automatic calibration for the ranges of effective porosity and capillary suction head at the wetted front for sand and the hydraulic conductivity as given in Rawls et al. [54], the runoff is only slightly overestimated at the first part of the rising limb and the runoff starts 80 seconds later than in the observations. But between the times of 580 and 921 seconds, the simulated hydrograph underestimated the observed one, leading to a peak discharge which is only $82 \%$ of the observed one (see Table 5, line 2; purple line with triangles in Fig. 6). With a NSE of 0.871, the overall agreement with the observed hydrograph is much better than with the average parameters for sand. Finally, optimization was carried out, where all Green-Ampt parameters (effective porosity, hydraulic conductivity, and capillary suction head) were varied in larger ranges, where the minimum and maximum values of the ranges from sand and loamy sand after Rawls et al. [54] were taken into account. Furthermore, also the initial soil water content as well as the friction coefficient were varied within the ranges given in Table 6 . The starting time of surface runoff as well as the peak discharge magnitude and time, and the overall shape of the observed hydrograph could be captured very well (see Table 5, line 3; blue line with diamonds in Fig. 6). With a NSE of 0.986 the performance is very good and comparable to the results, which were reported in Delfs et al. [10] (using a diffusive wave model for overland flow, Richards model for fluid movement in the unsaturated soil, and an interface layer concept for coupling) showing a NSE of 0.982 (see Table 5, line 4; black dots in Fig. 6). All simulations could not capture the slightly slower decrease in discharge towards the end of the recession limb, which was also reported in the simulation discussion in Smith and Woolhiser [64]. When using values for sand after Innovyze [27] surface runoff was even more overestimated, and the resulting NSE of -33.395 reflects the bad performance. Therefore, the values after Innovyze [27] were not further taken into account in Fig. 6 and Table 5. 


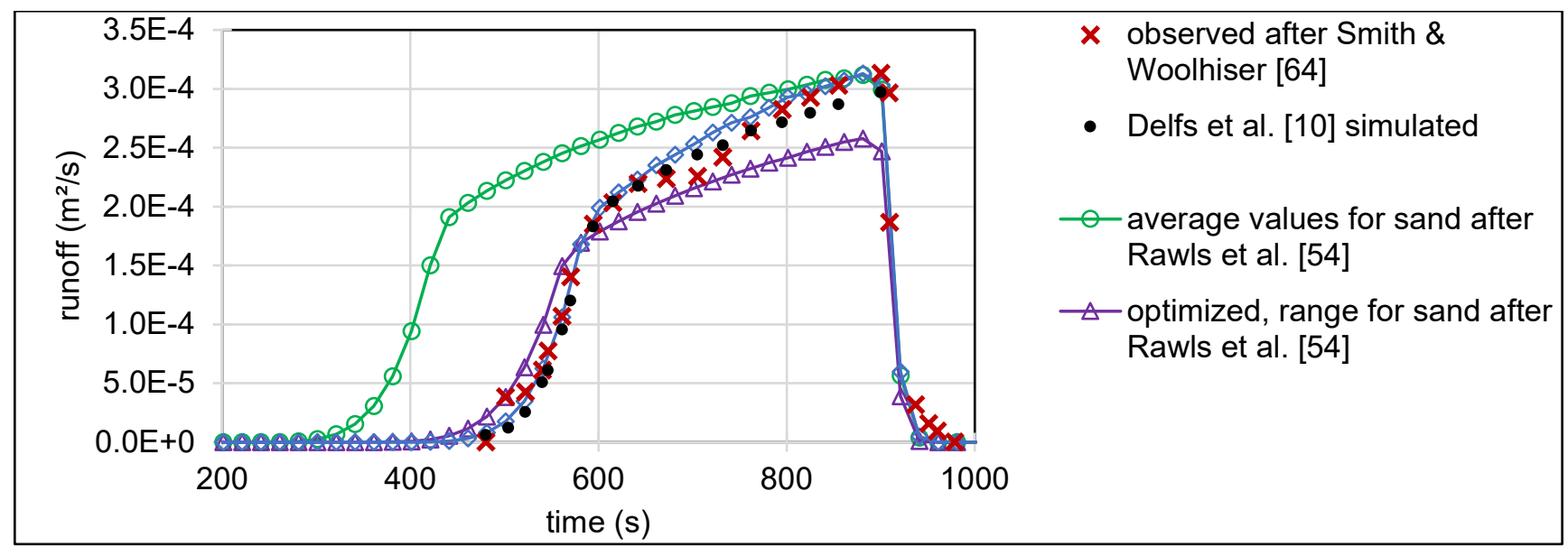

Fig. 6 Different simulated runoff hydrographs for for the laboratory experiment after Smith and Woolhiser [64]

Table 5 Different sets of Green-Ampt parameters for simulations of the rainfall-runoff experiment after Smith and Woolhiser [64]

\begin{tabular}{|c|c|c|c|c|c|c|c|}
\hline & \multirow{3}{*}{$\begin{array}{c}\text { Initial soil } \\
\text { water } \\
\text { content } \\
\theta_{\mathrm{i}} \\
\left(\mathrm{m}^{3} / \mathrm{m}^{3}\right)\end{array}$} & \multicolumn{3}{|c|}{ Green Ampt parameters } & \multirow{2}{*}{$\begin{array}{l}\text { Friction } \\
\text { Claminar }\end{array}$} & \multicolumn{2}{|c|}{ Performance } \\
\hline & & $\theta_{s}$ & $\mathrm{~K}$ & $h_{f}$ & & NSE & $K_{G} E_{n p}$ \\
\hline & & $\left(\mathrm{m}^{3} / \mathrm{m}^{3}\right)$ & $(\mathrm{m} / \mathrm{s})$ & $(\mathrm{m})$ & $\left(\mathrm{m}^{-1} \mathrm{~s}^{-1}\right)$ & - & - \\
\hline$\underset{\text { a) }}{\operatorname{average} \text { values for sand }}$ & 0.083 & 0.417 & $3.3 E-5$ & 0.049 & 1333333 & -0.245 & 0.553 \\
\hline $\begin{array}{c}\text { optimized, range for } \\
\text { sand a) }\end{array}$ & 0.080 & 0.397 & $3.3 E-5$ & 0.078 & 1333333 & 0.871 & 0.919 \\
\hline $\begin{array}{l}\text { optimized, range for } \\
\text { loamy sand - sand a) b) }\end{array}$ & 0.123 & 0.425 & $2.1 \mathrm{E}-5$ & 0.189 & 1328383 & 0.984 & 0.966 \\
\hline $\begin{array}{c}\text { Delfs et al. [10] (different } \\
\text { model) }\end{array}$ & 0.084 & 0.399 & $2.8 \mathrm{E}-5$ & - & 1333333 & 0.981 & 0.951 \\
\hline
\end{tabular}

a) after Rawls et al. [54], b) and calibration of $\theta_{i}$ and $C_{\text {laminar (see Table 5) }}$

In Figure 7 the infiltration rates for the different parameter sets are shown, and as there are no observed infiltration rates available, compared to the ones simulated from Delfs et al. [10] (black dots in Fig. 7). Again, the underestimation of infiltration when considering average Green-Ampt parameters for sand after Rawls et al. [54] is visible in the lower infiltration rates (green line with circles in Fig. 7). The infiltration rate with optimized parameters for the ranges of sand (purple line with triangles in Fig.7) agrees well with the one simulated by Delfs et al. [10] until the time of 480 seconds and overestimates it afterwards. With optimized parameters for the larger ranges between loamy sand and sand it is the other way round (blue line with diamonds in Fig. 7). 


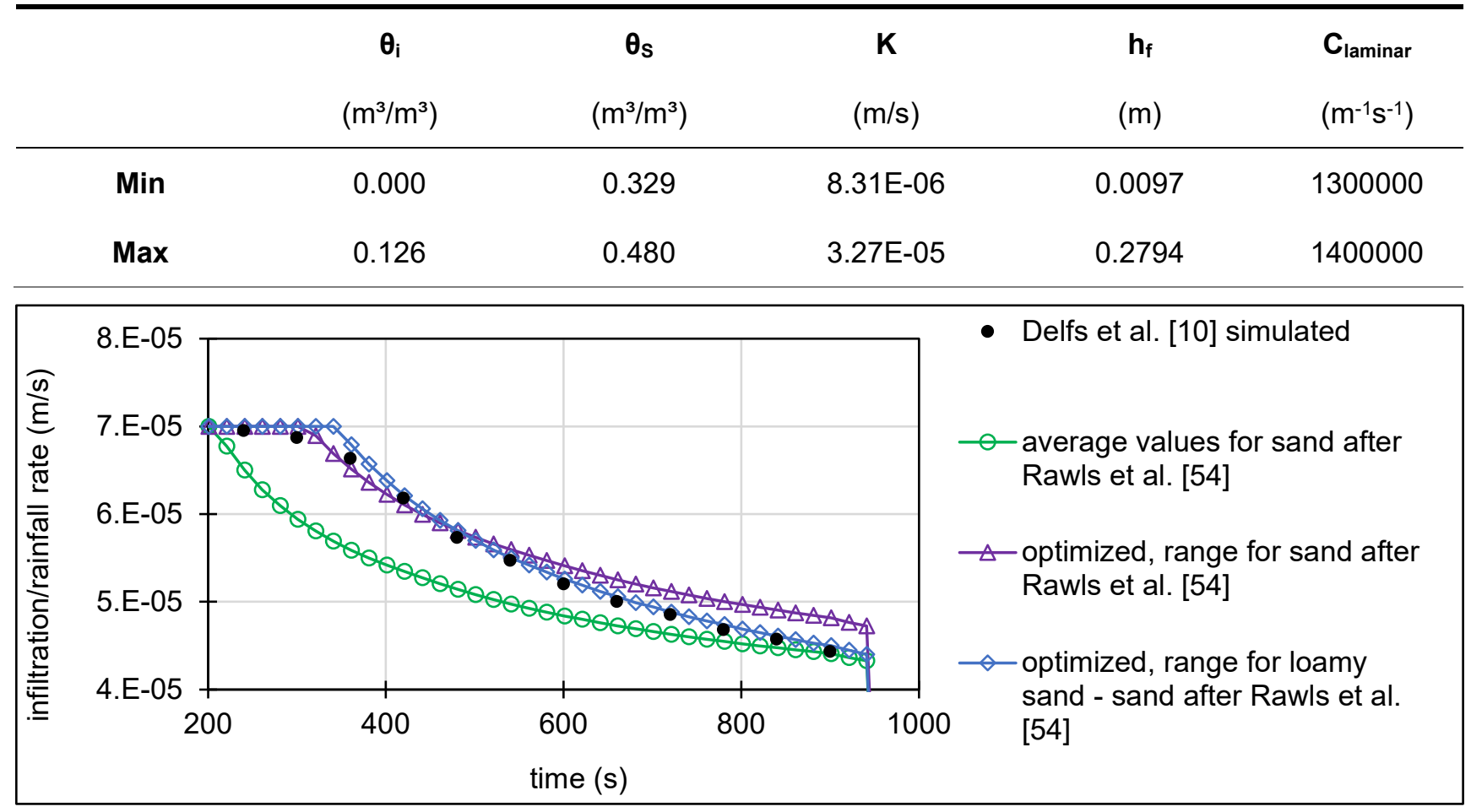

Fig. 7 Infiltration rates over time for different simulations of the experiment after Smith and Woolhiser [64]

\subsection{Test case 2 - Laboratory experiment for loam (Limburg) after Lima [35]}

Figure 8 shows the hydrographs for the loam soil of Limburg when considering different Green-Ampt parameters compared to the observed one. The corresponding parameter sets as well as indicators for the goodness-of-fit are given in Table 7. Similar to the test case of the Smith and Woolhiser experiment (Section 3.1), surface runoff is strongly overestimated when considering the average Green-Ampt parameters for loam after Rawls et al. [54] and starts about 180 seconds earlier than the observed one. The peak discharge is about $17 \%$ higher than the observed one, and the NSE for the overall hydrograph is -1.186 , and the KGEnp is 0.2 indicating both a bad agreement to the observations (see Table 7, line 1; green line with circles in Fig. 8). The friction was set to 0.020 $\mathrm{sm}^{-1 / 3}$, which is the recommended value for bare clay loam after Engman [12]. The result when using the optimized parameters within the ranges for loam after Rawls et al. [54] agrees well with the measurements. The start time of surface runoff as well as the overall hydrograph shape are well captured, but the peak discharge is underestimated and only $86 \%$ of the observed one. The NSE is 0.928 and the KGEnp is 0.924 (see Table 7, line 2; purple line with triangles in Fig. 8). Almost the same hydrograph with an NSE of 0.930 and KGE $\mathrm{K}_{n \mathrm{p}}$ of 0.927 was simulated when using the measured and estimated values of saturated soil water content and the hydraulic conductivity after Lima [35], and calibrating only the capillary suction head $h_{f}$ and Manning's friction coefficient (see Table 7, line 3; blue line with diamonds in Fig. 8). For both cases, Manning's friction coefficient was calibrated 


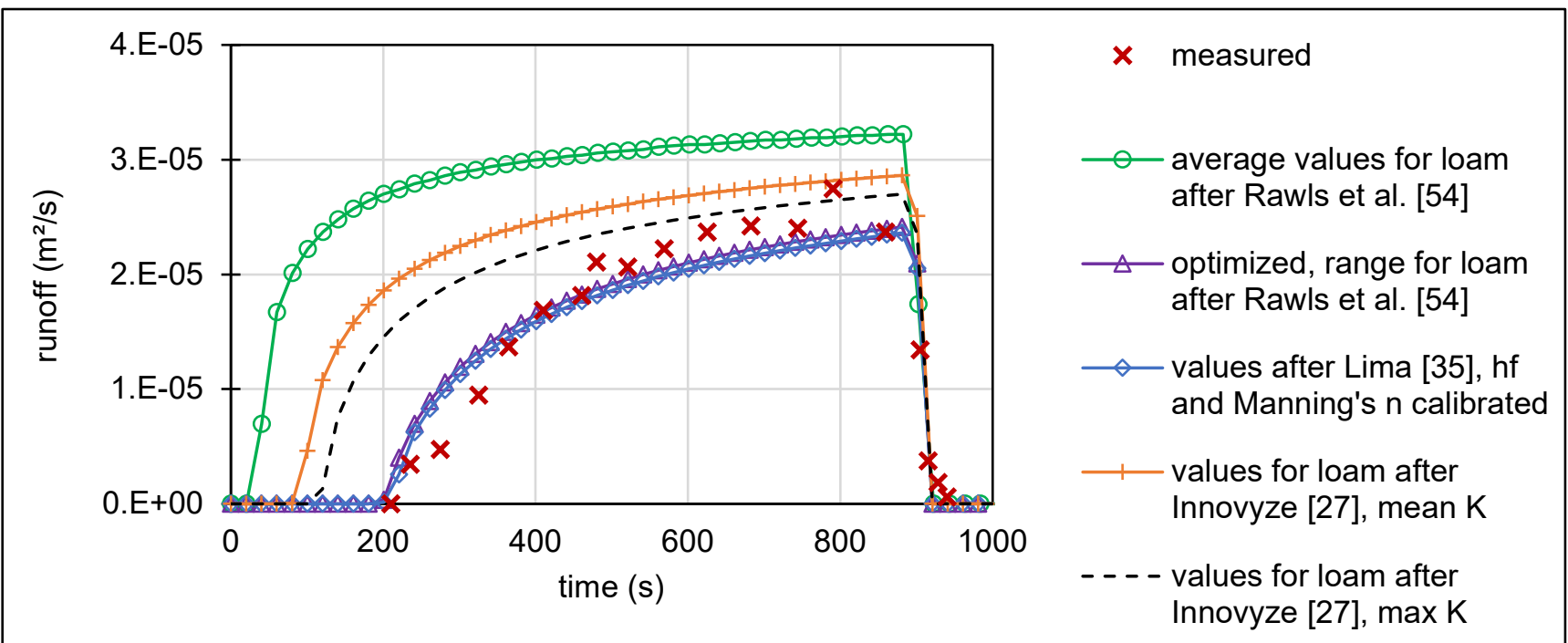

Fig. 8 Runoff hydrographs for different simulations of the experiment for loamy soil after Lima [35]

within the range of $0.010-0.033 \mathrm{sm}^{-1 / 3}$, representing the range from bare sand to bare clay loam after Engman [12], and resulting value was $0.021 \mathrm{sm}^{-1 / 3}$ in both cases, and therefore very close to the recommended value of $0.020 \mathrm{sm}^{-1 / 3}$ for clay loam after Engman [12]. The capillary suction head was calibrated within the range for loam after Rawls et al. [54]. The fact that two parameter sets with significantly different values for hydraulic conductivity and capillary suction head generated almost the same hydrographs, emphasizes the problem of equifinality during the calibration process of several calibration parameters that depend on each other. A higher hydraulic conductivity can be sort of "compensated" by a lower capillary suction head, although the different processes of capillary-driven and gravity-driven infiltration are dominating at different states of soil water content and therefore different times of the rainfall event. Taking into account the average values for loam after Innovyze [27] with the mean value for the hydraulic conductivity after Akan [2], lead to better results than with average values after Rawls et al. [54] (see Table 7, line 4; orange line with plus signs in Fig. 8). But with a NSE of 0.045 the results are still much worse than the results with calibrated parameters, where the NSE is 0.928 . When taking instead of the mean the maximum value for the hydraulic conductivity after Akan [2], the results improved but still strongly underestimate infiltration leading to a NSE of 0.429 (see Table 7, line 5; black dashed line Fig. 8). Figure 9 presents the infiltration rates, and it clearly shows, that in the case of average values for loam (green line with circles in Fig. 9), the infiltration rate shortly reaches the maximum value of rainfall intensity, but directly starts to drop after the first time step. For the two cases with calibrated parameters the infiltration rates just start to decrease after 180 seconds and decrease much slower (purple line with triangles and blue line with diamonds in Fig. 9). When considering the values for loam after Innovyze [27] with the mean value for the hydraulic conductivity, the infiltration rate starts to decrease after 80 seconds (orange line with plus signs in Fig. 9), and after 120 seconds if the maximum value for the hydraulic conductivity was taken (black dashed line in Fig. 9). As 
the infiltration rate was not directly measured, the difference between rainfall and observed runoff was taken as reference.

Table 7 Different sets of Green-Ampt parameters for simulations of the rainfall-runoff experiment on loamy soil after Lima [35]

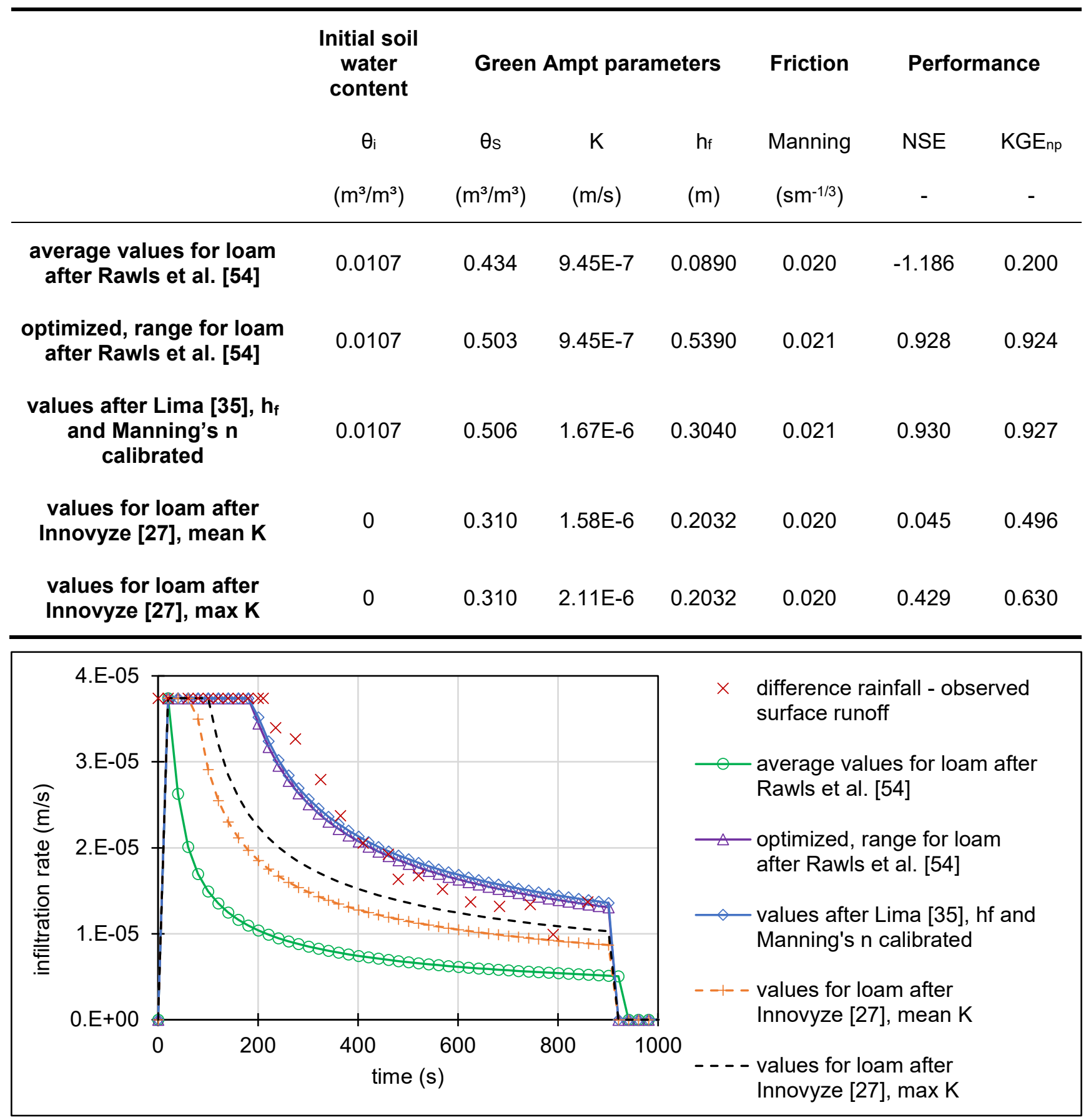

Fig. 9 Infiltration rates over time for different simulations of the experiment for loamy soil after Lima [35]

\subsection{Test case 3 - Laboratory experiment for clay loam (Alentejo) after Lima [35]}

Figure 10 shows the hydrographs for the clay loam soil of Alentejo, and the corresponding parameter sets as well as indicators for the goodness-of-fit are given in Table 8. When having in mind the two other test cases 
presented before, it is remarkable that in this case the simulated hydrograph agrees well with the observed one when considering the average values for clay loam after Rawls et al. [54]. The surface runoff is only slightly overestimated and starts about 60 seconds earlier than the observed one. The NSE of 0.724 and KGE $E_{n p}$ of 0.808 indicate a relatively good agreement as well (see Table 8, line1; green line with circles in Fig. 10). The Manning coefficient was set to $0.020 \mathrm{sm}^{-1 / 3}$ corresponding to the recommended value for bare clay loam after Engman [12] . Another simulation was done considering the values from optimization when taking into account the ranges for clay loam for the effective porosity and the capillary suction head and the average value of hydraulic conductivity after Rawls et al. [54], and for the Manning coefficient a range between 0.012 and $0.033 \mathrm{sm}^{-1 / 3}$ corresponding to the range for bare clay loam after Engman [12]. Surface runoff starts approximately 20 seconds before the observed one, leading to a slight overestimation of runoff at the beginning. After about 100 seconds until the end, the simulated hydrograph slightly underestimates the observed one. The NSE of 0.924 and KGEnp of 0.862 are a little bit higher than for the average values for clay loam (see Table 8, line 2; purple line with triangles in Fig. 10). When taking the measured and estimated values for the saturated soil water content and the hydraulic conductivity after Lima [35] and calibrating only the Manning's coefficient and capillary suction head, the results show a very similar hydrograph, but surface runoff starts about 40 seconds before the measured one, first slightly overestimates the measured runoff and after about 120 seconds underestimates it. The NSE of 0.888 is slightly below the one for the optimized parameters, while the KGEnp is slightly higher (see Table 8, line 3; blue line with diamonds in Fig. 10). For these two cases, where also Manning's coefficient was calibrated, values of 0.033 and $0.032 \mathrm{sm}^{-1 / 3}$, respectively, were obtained being at the upper bound of the range for bare clay loam after Engman [12]. Taking into account the average values for clay loam after Innovyze, the results are slightly worse than with average values after Rawls et al. [54] when taking the mean value for the hydraulic conductivity after Akan [2] (see Table 8, line 4; orange line with plus signs in Fig. 10), and slightly better when taking into account the maximum value for the hydraulic conductivity after Akan [2] (see Table 8, line 5; black dashed line in Fig. 10). Manning's coefficient was not calibrated here but fixed to be $0.020 \mathrm{sm}^{-1 / 3}$ representing the recommended value for bare clay loam to simulate the case that there is no runoff data available for calibration. If Manning's coefficient was calibrated also here, it resulted also in a value of $0.033 \mathrm{sm}^{-1 / 3}$, but the impact on the hydrograph was minor. 


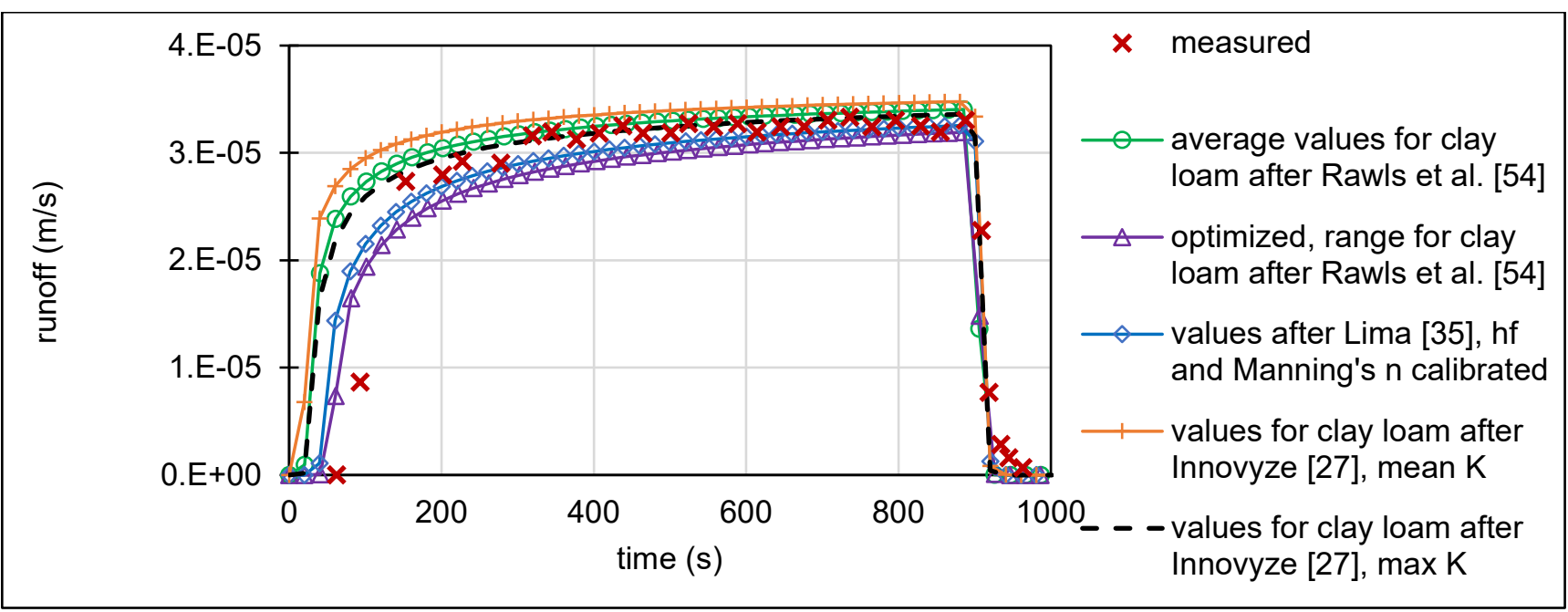

Fig. 10 Runoff hydrographs for different simulations of the experiment after Lima for clay loam [35]

Table 8 Different sets of Green-Ampt parameters for simulations of the rainfall-runoff experiment on clay loam after Lima [35]

\begin{tabular}{|c|c|c|c|c|c|c|c|}
\hline & \multirow{3}{*}{$\begin{array}{c}\text { Initial soil } \\
\text { water } \\
\text { content } \\
\theta_{i} \\
\left(\mathrm{~m}^{3} / \mathrm{m}^{3}\right)\end{array}$} & \multicolumn{3}{|c|}{ Green Ampt parameters } & \multirow{3}{*}{$\begin{array}{l}\text { Friction } \\
\text { Manning } \\
\left(\mathrm{sm}^{-1 / 3}\right)\end{array}$} & \multicolumn{2}{|c|}{ Performance } \\
\hline & & $\theta_{\mathrm{s}}$ & $\mathrm{K}$ & $h_{f}$ & & NSE & $K_{G E}$ \\
\hline & & $\left(m^{3} / m^{3}\right)$ & $(\mathrm{m} / \mathrm{s})$ & $(\mathrm{m})$ & & - & - \\
\hline $\begin{array}{c}\text { average values for clay } \\
\text { loam after Rawls et al. } \\
\text { [54] }\end{array}$ & 0.006 & 0.309 & $2.77 \mathrm{E}-7$ & 0.209 & 0.020 & 0.724 & 0.808 \\
\hline $\begin{array}{c}\text { optimized, range for clay } \\
\text { loam after Rawls et al. } \\
\text { [54] }\end{array}$ & 0.006 & 0.390 & $2.77 \mathrm{E}-7$ & 0.479 & 0.033 & 0.924 & 0.862 \\
\hline $\begin{array}{c}\text { values after Lima [35], } \mathbf{h}_{\boldsymbol{f}} \\
\text { and Manning's } n \\
\text { calibrated }\end{array}$ & 0.006 & 0.411 & $1.13 \mathrm{E}-7$ & 0.857 & 0.032 & 0.888 & 0.876 \\
\hline $\begin{array}{l}\text { values for clay loam after } \\
\text { Innovyze [27], mean K }\end{array}$ & 0 & 0.240 & $1.81 \mathrm{E}-7$ & 0.254 & 0.020 & 0.668 & 0.823 \\
\hline $\begin{array}{l}\text { values for clay loam after } \\
\text { Innovyze [27], max K }\end{array}$ & 0 & 0.240 & 3.61E-7 & 0.254 & 0.020 & 0.801 & 0.857 \\
\hline
\end{tabular}

\subsection{Test case 4 - Field experiment in Thiès catchment, Senegal [66]}

The simulated hydrographs of different parameter sets are compared to the measured data in Figure 11, the different parameter sets as well as goodness-of-fit indicators are given in Table 9. If the average values for sand 
after Rawls et al. [54] are considered, infiltration is completely overestimated as no surface runoff occurs, which leads to an NSE of -5.05 (see Table 9, line 1; green dotted line in Fig. 11). When considering instead the average values for loamy sand, the simulated hydrograph agrees much better with the observed one, but still underestimates it most of the time. The overall NSE is 0.520 and the $\mathrm{KGE}_{n p}$ is 0.656 (see Table 9, line 2; orange dashed line in Fig. 11). When taking instead the values for sand after Innovyze with the mean value for the hydraulic conductivity after Akan [2] into account, the second one of the two smaller peaks in the beginning of the observed hydrograph is relatively well captured, while the rest of the hydrograph is strongly overestimated (see Table 9, line 3; purple plus signs in Fig. 11). The overall NSE is 0.417 indicating a much better fit than with the average values for sand after Rawls et al. [54]. The $\mathrm{KGE}_{\mathrm{np}}$ of 0.660 gives a better agreement than with the average values for loamy sand after Rawls et al. [54]. Considering the values after Innovyze with the maximum value for the hydraulic conductivity after Akan [2] results in an improved hydrograph with a NSE of 0.628 and a KGEnp of 0.731 , but still clearly underestimates infiltration (see Table 9, line 4; light blue rectangles in Fig. 11). The optimization was carried out for the range of sand after Rawls et al. [54], however a decreased lower threshold according to the calibrated value in Simons [62] was used for the hydraulic conductivity. The hydrograph resulting from the optimized parameters does not capture the measured two smaller peaks in the beginning of the observed runoff, but later on it fits the observations relatively well, leading to an overall NSE of 0.810 (see Table 9, line 5; dark blue solid line in Fig. 11). A last simulation was done considering the modified Green-Ampt model with an effective hydraulic conductivity of crust and subcrust soil as given in Equation 8 in Section 2.2. To exemplarily see the effect of this modification accounting for a surface crust, one simulation with the average values for sand after Rawls et al. [54] for the subcrust soil, and a crust of $5 \mathrm{~mm}$ thickness and with an hydraulic conductivity of $1.09 \mathrm{E}-6 \mathrm{~m} / \mathrm{s}$, which is 30 times lower than the one for the subcrust soil $(3.27 \mathrm{E}-5 \mathrm{~m} / \mathrm{s})$, was carried out. The simulated hydrograph considering such crust captures very well the beginning of surface flow in terms of the first smaller peaks, although it overestimates these peaks by about $35 \%$. After about 800 seconds, the simulated hydrograph starts to continuously decrease and reaches zero after about 1900 seconds, while the observed one is continuously increasing. Therefore, the simulated values strongly underestimate the observed ones, which leads to an overall bad performance with a NSE of -4.823 (see Table 9, line 6; grey triangles in Fig. 11). As shown in Equation 8 in Section 2.2, the effective hydraulic conductivity equals the crust hydraulic conductivity as long as the wetted depth is smaller than the crust thickness, and is calculated by a harmonic mean between the hydraulic conductivities of the crust and subcrust soil, when the wetted depth is larger than the crust thickness. Therefore, with increasing time, the infiltration increases due to a stronger impact of the hydraulic conductivity of the subcrust soil on the effective hydraulic conductivity. 


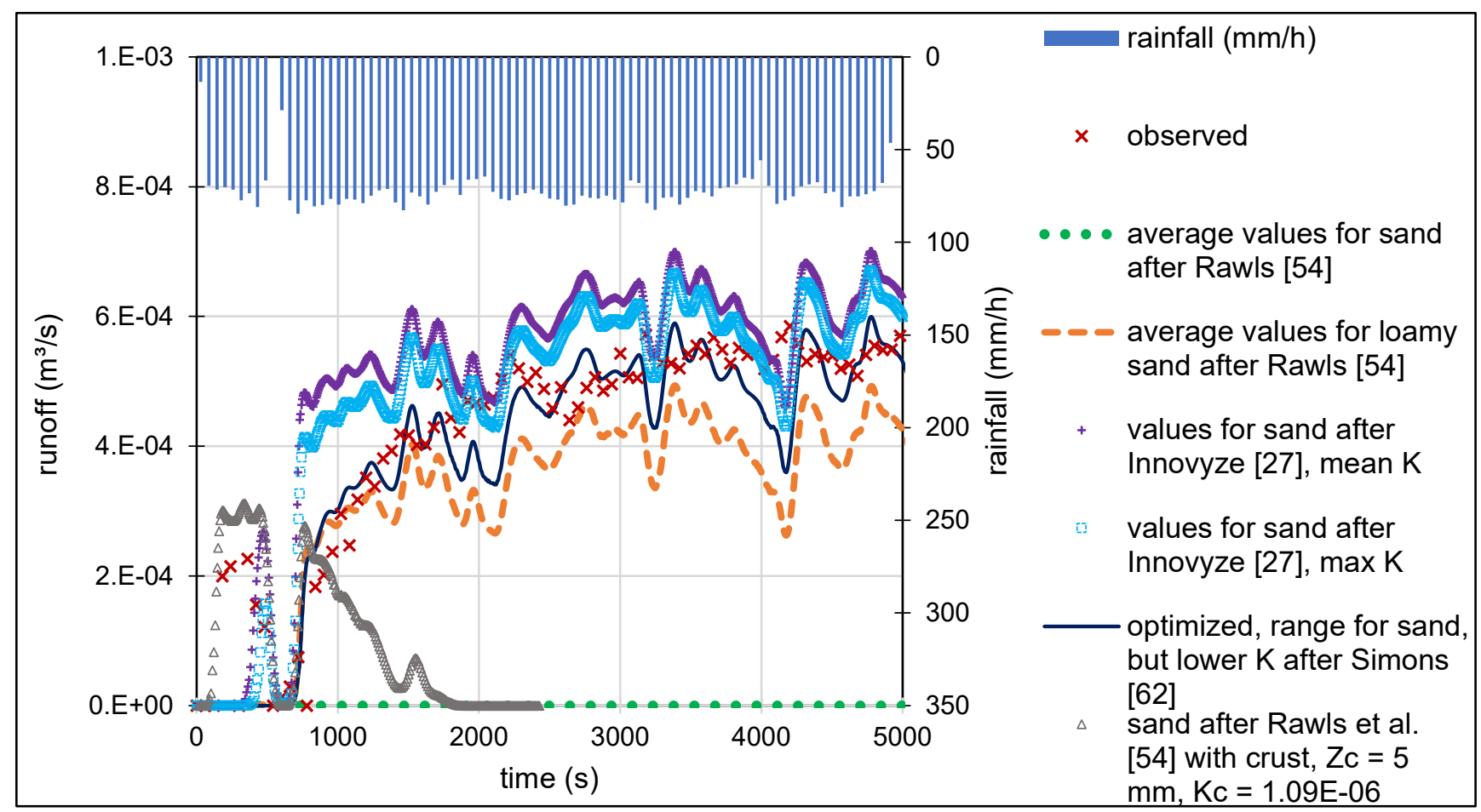

Fig. 11 Runoff hydrographs for different simulations of the rainfall-runoff experiment in the Thiès catchment in Senegal

Table 9 Different sets of Green-Ampt parameters for simulations of the rainfall-runoff experiment in the Thiès catchment in Senegal

\begin{tabular}{|c|c|c|c|c|c|c|}
\hline & \multirow{3}{*}{$\begin{array}{c}\begin{array}{c}\text { Initial } \\
\text { water } \\
\text { content }\end{array} \\
\theta_{i} \\
\left(\mathrm{~m}^{3} / \mathrm{m}^{3}\right)\end{array}$} & \multicolumn{3}{|c|}{ Green Ampt parameters } & \multicolumn{2}{|c|}{ Performance } \\
\hline & & $\theta s$ & $\mathrm{~K}$ & $h_{f}$ & NSE & $K_{G E}$ \\
\hline & & $\left(\mathrm{m}^{3} / \mathrm{m}^{3}\right)$ & $(\mathrm{m} / \mathrm{s})$ & $(\mathrm{m})$ & - & \\
\hline $\begin{array}{l}\text { average values for sand after } \\
\text { Rawls et al. [54] }\end{array}$ & 0.20 & 0.417 & 3.27E-5 & 0.0495 & -5.052 & -1.125 \\
\hline $\begin{array}{l}\text { average values for loamy sand } \\
\text { after Rawls et al. [54] }\end{array}$ & 0.20 & 0.401 & $8.31 \mathrm{E}-06$ & 0.0613 & 0.520 & 0.656 \\
\hline $\begin{array}{l}\text { values for sand after Innovyze } \\
\text { [27], mean K }\end{array}$ & $\begin{array}{l}\text { Initial soil } \\
\text { moisture } \\
\text { deficit }\end{array}$ & 0.340 & $2.64 \mathrm{E}-06$ & 0.1016 & 0.417 & 0.660 \\
\hline $\begin{array}{l}\text { values for sand after Innovyze } \\
\text { [27], max K }\end{array}$ & $\begin{array}{l}\text { Initial soil } \\
\text { moisture } \\
\text { deficit }\end{array}$ & 0.340 & $3.17 \mathrm{E}-06$ & 0.1016 & 0.628 & 0.731 \\
\hline $\begin{array}{l}\text { optimized, range for sand, but } \\
\text { lower K from calibration after } \\
\text { Simons [62] }\end{array}$ & 0.20 & 0.378 & $4.50 \mathrm{E}-06$ & 0.1920 & 0.810 & 0.788 \\
\hline $\begin{array}{c}\text { sand with crust, } Z_{c}=5 \mathrm{~mm}, \\
K_{c}=1.09 \mathrm{E}-06\end{array}$ & 0.20 & 0.417 & $3.27 \mathrm{E}-05$ & 0.0495 & -4.823 & -1.064 \\
\hline
\end{tabular}




\subsection{Case study - Flash flood simulations in El Gouna, Egypt}

Figure 12 shows the water depths in the model domain after 9 hours of simulation time considering infiltration with 1) average values for loam after Rawls et al. [54] and 2) average values for sand after Rawls et al. [54] combined with a surface crust of $5 \mathrm{~mm}$ with a hydraulic conductivity for clay after Rawls et al. [54] and a Manning's friction coefficient of $n=0.01 \mathrm{sm}^{-1 / 3}$ according to the average value for bare sand, and $\mathrm{n}=0.02 \mathrm{sm}^{-1 / 3}$ according to the average value for bare clay loam after Engman [12], respectively. Comparing the results with infiltration for loam and for sand with a crust of $5 \mathrm{~mm}$, it becomes obvious that for loam the local rainfall inside the model domain almost completely infiltrated, while for sand with a $5 \mathrm{~mm}$ thick crust, flooding areas apart from the main stream coming from Wadi Bili were generated, which better agrees with the observations reported by the community. Strong damages were for example reported at construction sites along the shore of one lagoon in the South of El Gouna, where the flow was draining into the lagoon. These inundation areas and the stream draining into the lagoon are captured when considering sand with a crust of $5 \mathrm{~mm}$, but are completely dry when considering loam. Also, other inundated areas in El Gouna have been documented by photographs and confirmed by shop owners. These inundated areas are not represented in the case of loam as the water directly infiltrates, while they are captured to a certain extent when considering sand with a crust. When comparing the results from different friction coefficients, the significant effect of the friction becomes obvious, as the flood wave from Wadi Bili propagates much slower, and therefore more infiltration can take place leading to overall smaller water depth. This becomes even clearer in Figure 13, where the temporal development of water depth at the location indicated with a red circle in Figure 12 is shown for different simulations. While the effect of friction is less pronounced when no infiltration is considered, it gets more important when considering either infiltration for loam or for sand with a surface crust of $5 \mathrm{~mm}$. With a friction coefficient of $\mathrm{n}=0.02 \mathrm{sm}^{-1 / 3}$, the peak water depth for sand with crust (orange line with rectangles in Fig. 14) is about $60 \%$ smaller compared to the result with $n=0.01 \mathrm{sm}^{-1 / 3}$ (purple line with triangles in Fig. 14) and occurs about three hours later. For loam, the peak water depth with $n=0.02$ $\mathrm{sm}^{-1 / 3}$ (dark blue dashed line in Fig. 13) is about $58 \%$ smaller and 10 hours later than with $\mathrm{n}=0.01 \mathrm{sm}^{-1 / 3}$ (light blue line with crosses in Fig. 13). For the consideration of sand with a crust, the infiltration in the first hours of simulation time is lower compared to loam, so that the local rainfall around that location already generated some surface runoff leading to water depths of a few centimeters at the considered location before the flood wave reaches the location. Shortly after the flood wave has passed the location, the water depth drops to zero, which can be explained by the fact that the wetted depth increased so that the impact of the hydraulic conductivity of the underlying sand is dominating rather than the one of the surface crust. When considering loam, which has a 
lower hydraulic conductivity than sand but a higher one than the clay of the crust, the infiltration in the beginning is much higher and almost no surface runoff is generated by the local rainfall, as almost all water directly infiltrated. In the case of a friction coefficient of $n=0.01 \mathrm{sm}^{-1 / 3}$, the peak water depth occurs about three hours later for loam than for sand with crust and is about $23 \%$ smaller. On the other hand, the water stays much longer at the location also after the flood wave is over, which is due to the higher volume of water that infiltrated already at the beginning causing a faster saturation of the soil. As the hydraulic conductivity is the limiting factor when the saturation increased and the capillary suction has no strong influence anymore, the water from the flood wave infiltrates much slower than in the case of sand with crust, where at later time steps the effective hydraulic conductivity is dominated by the one of the sand below the crust. Taking into account the values for sand after Innovyze with the minimum value for the hydraulic conductivity (grey line with dots in Fig. 13) results in a peak water depth of $16 \mathrm{~cm}$ after about 15.5 hours, which is much more plausible than the result for average values for sand and loamy sand after Rawls et al. [54] (black line with plus signs in Fig. 13), where no water depth occurred at the considered location. But similar to the case of loam, the local rainfall around that location directly infiltrated, so that only the flood wave coming from Wadi Bili generated water depths, while the flooding areas induced from the locally fallen rainfall is not captured, and infiltration is therefore still overestimated. On the other hand, similar to the results for loam, the water stays for a longer time after the flood and rainfall event, which in turn agrees better with the observations than the results of sand with a crust, where the water depth drops to zero almost directly after the flood wave has passed. Therefore, a combination of the average values after Innovyze [27] combined with a thin surface crust of lower hydraulic conductivity could lead to the overall most plausible results. 

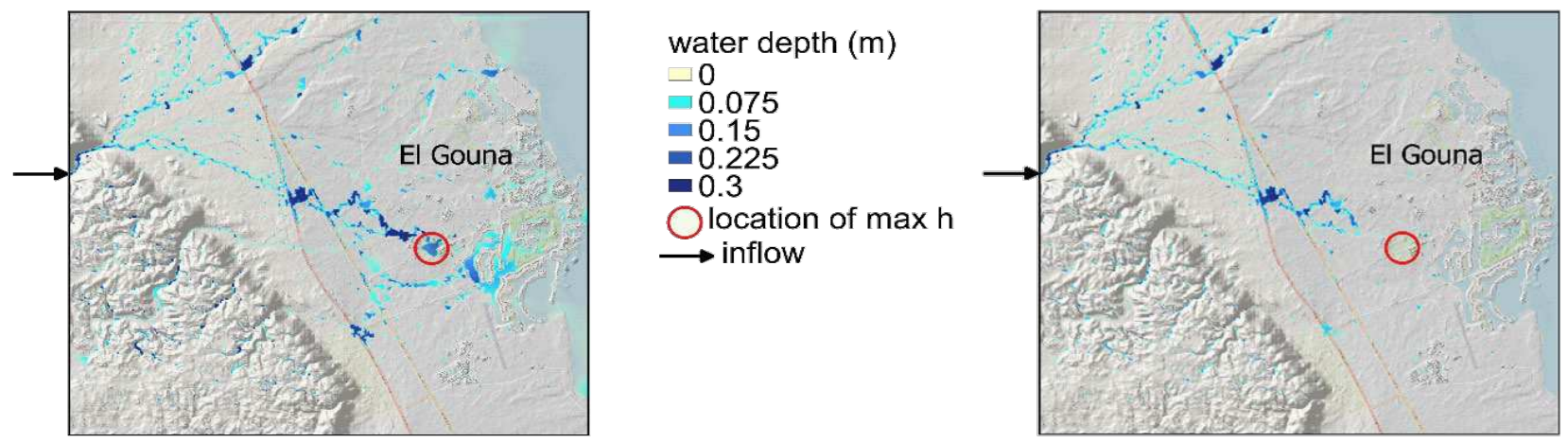

sand with crust, $\mathrm{Zc}=5 \mathrm{~mm}, \mathrm{Kc}=$ Kclay, $\mathrm{n}=0.02 \mathrm{sm}^{-1 / 3}$

loam, $\mathrm{n}=0.02 \mathrm{sm}^{-1 / 3}$
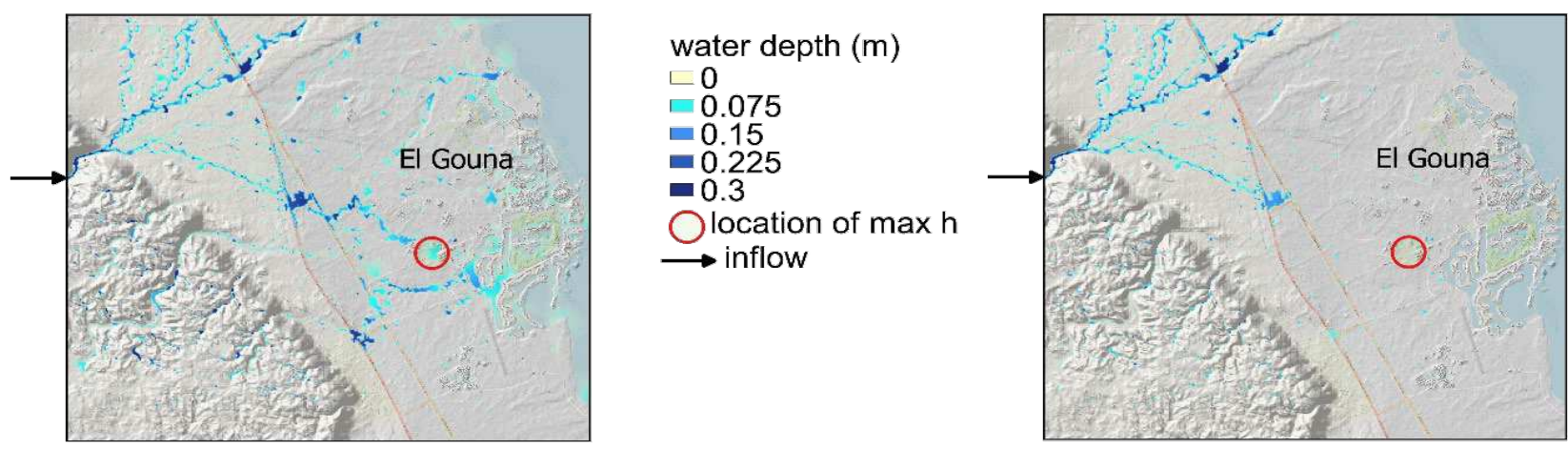

Fig. 12 Water depth distributions in the model domain after 9 hours of simulation time considering different values for Infiltration and friction parameteters. Zc : crust thickness, Kc: hydraulic conductivity of crust, Kclay: hydraulic conductivity for clay after Rawls et al. [54], see Table 1, n: Manning's friction coefficient (background map: @OpenStreetMap contributors)
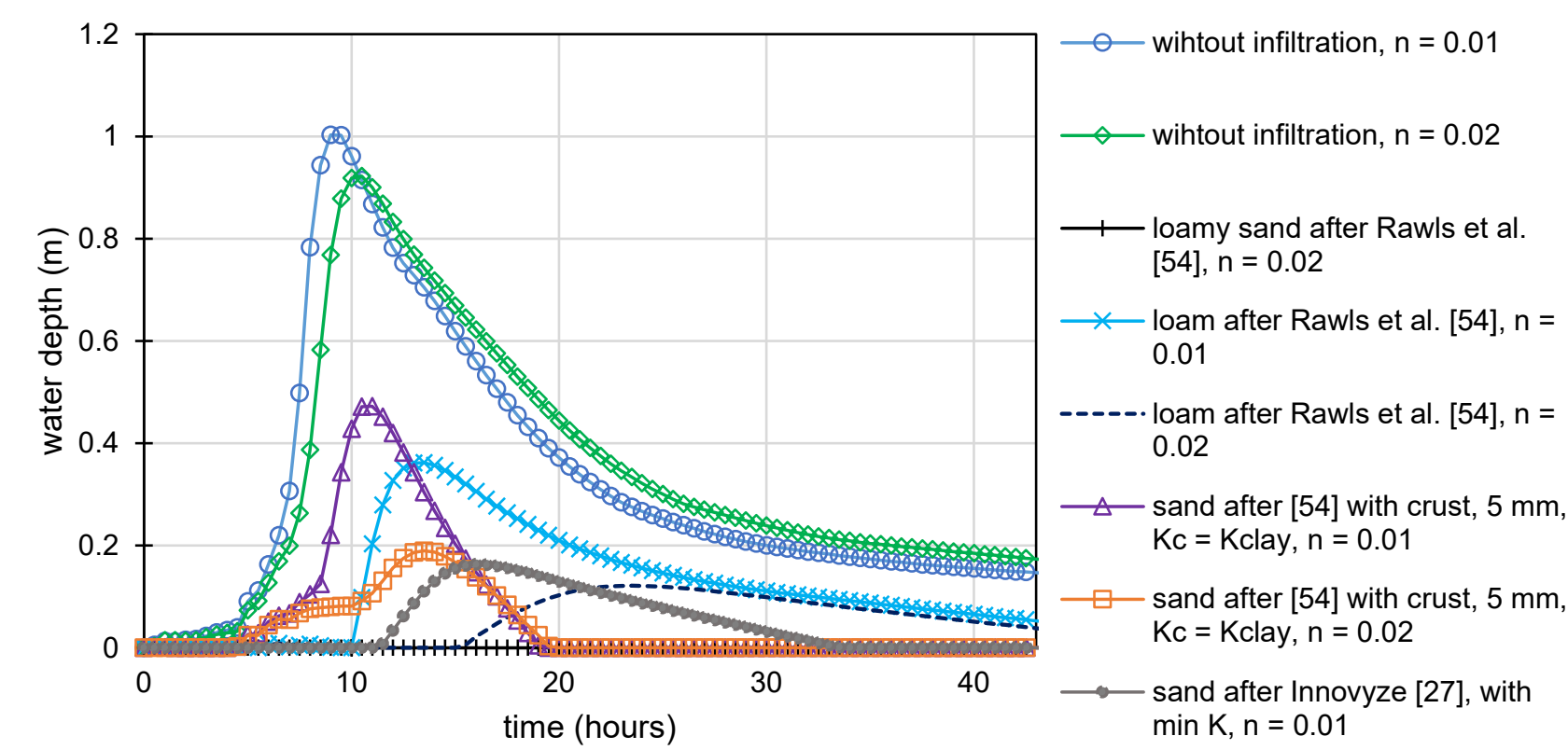
0.01

----- loam after Rawls et al. [54], $n=$ 0.02

$\triangle$ sand after [54] with crust, $5 \mathrm{~mm}$, $\mathrm{Kc}=$ Kclay, $\mathrm{n}=0.01$

$\square$ sand after [54] with crust, $5 \mathrm{~mm}$, $\mathrm{Kc}=$ Kclay, $\mathrm{n}=0.02$

$\longrightarrow$ sand after Innovyze [27], with $\min \mathrm{K}, \mathrm{n}=0.01$

Fig. 13 Temporal development of simulated water depths at location of maximum water depth indicated with a red circle in Fig. 12, considering different infiltration settings and values of Manning's friction coefficient. K: hydraulic conductivity, Kc: hydraulic conductivity of crust, $n$ : Manning's friction coefficient in $\mathrm{sm}^{-1 / 3}$ 


\subsection{Overview of calibrated parameter sets for all cases}

Table 10 summarizes the optimum parameter sets resulting from the calibration process in test cases $1-4$ and the plausibility analysis for the case study in El Gouna. For the case study of El Gouna, the given parameter set did still not lead to satisfying results, as no flooding areas from the local rainfall have been simulated although they have been observed by the community.

Table 10 Overview of calibrated parameter sets for all cases

\begin{tabular}{|c|c|c|c|c|c|c|c|}
\hline Case & Texture & $\begin{array}{c}\theta_{\mathrm{i}} \\
\left(\mathrm{cm}^{3} / \mathrm{cm}^{3}\right)\end{array}$ & $\begin{array}{c}\theta_{\mathrm{s}} \\
\left(\mathrm{cm}^{3} / \mathrm{cm}^{3}\right)\end{array}$ & $\begin{array}{c}\mathbf{K} \\
(\mathrm{cm} / \mathrm{h})\end{array}$ & $\begin{array}{c}\mathbf{h}_{\mathbf{f}} \\
(\mathrm{cm})\end{array}$ & Friction & $\begin{array}{l}\text { NSE } \\
(-)\end{array}$ \\
\hline Test case 1 & Sand & 0.123 & 0.425 & 7.56 & 18.90 & $\begin{array}{c}\text { Claminar } \\
1328383 \mathrm{~m}^{-1} \mathrm{~s}^{-1}\end{array}$ & 0.984 \\
\hline Test case 2 & Loam & 0.0107 & 0.503 & 0.34 & 53.90 & $\begin{array}{c}\text { Manning } \\
0.021 \mathrm{sm}^{-1 / 3}\end{array}$ & 0.928 \\
\hline Test case 3 & $\begin{array}{l}\text { Clay } \\
\text { loam }\end{array}$ & 0.006 & 0.390 & 0.10 & 47.90 & $\begin{array}{c}\text { Manning } \\
0.033 \mathrm{sm}^{-1 / 3}\end{array}$ & 0.924 \\
\hline Test case 4 & Sand & 0.20 & 0.378 & 1.62 & 19.20 & $\begin{array}{c}\mathrm{n}_{0}: 0.014 \mathrm{sm}^{-1 / 3} \\
\mathrm{~h}_{0}=0.0045 \mathrm{~m} \text { and } \varepsilon \\
=0.1^{*}\end{array}$ & 0.810 \\
\hline Case study & $\begin{array}{l}\text { Sand, } \\
\text { loam }\end{array}$ & 0.03 & 0.434 & 0.34 & 8.89 & $\begin{array}{l}\text { Manning } \\
0.01 \mathrm{sm}^{-1 / 3}\end{array}$ & - \\
\hline
\end{tabular}

$\theta_{\mathrm{i}}$ : initial soil water content, $\theta_{\mathrm{s}}$ : effective porosity, $\mathrm{K}$ : hydraulic conductivity; $\mathrm{h}_{\mathrm{f}}$ : capillary suction at wetted front; *depth-dependent Manning 


\subsection{Percentual differences of optimum values from average values after Rawls et al. [54]}

Figure 14 shows the improvements of the Nash-Sutcliffe efficiency as well as the corresponding percental changes of initial soil moisture deficit $(\Delta \theta)$, hydraulic conductivity $(K)$ and capillary suction head at the wetted front $\left(h_{f}\right)$ for the two best performing parameter sets of each test case when compared to the average values after Rawls et al. [54], called reference simulation in the following. The NSE could be significantly improved by $112 \%$ and $123 \%$ for Test 1,211 and $212 \%$ for Test 2 and by even 586 and $568 \%$ for Test 4 , while the improvement for Test 3 was with $20 \%$ and $16 \%$ much lower as the reference simulation already gave relatively good results.

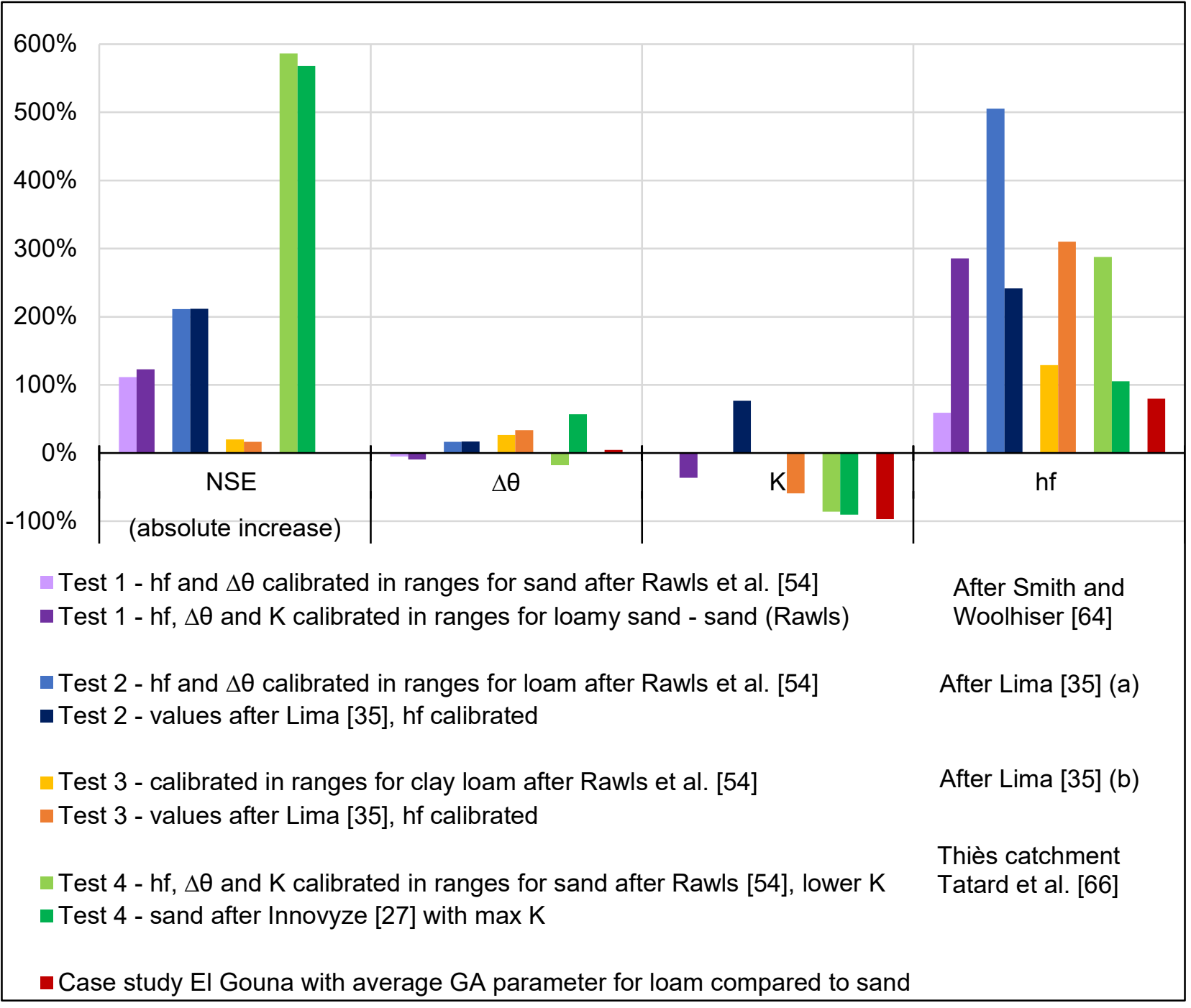

Fig. 14 Percental changes of the Green-Ampt (GA) parameters for each test case compared to the average values after Rawls et al. [54]. NSE: Nash-Sutcliffe efficiency, $\Delta \theta$ : initial soil moisture deficit, K: hydraulic conductivity, hf: capillary suction head and wetted front, $n$ : Manning's friction coefficient, max K: maximum hydraulic conductivity after Innovyze [27] according to Akan [2] (see Table 2) 
As a result of the automatic calibration, the initial soil moisture deficit negligibly decreased in both shown parameters sets for the laboratory experiment after Smith and Woolhiser [64] (Test 1). The hydraulic conductivity was fixed in the case where the automatic calibration was carried out within the ranges for sand after Rawls et al. [54] (see Table 1), and decreased by $36 \%$ when calibration was carried out within the ranges for loamy sand to sand after Rawls et al. [54]. The capillary suction head at the wetted front significantly increased in both parameter sets leading to higher infiltration rates, and therefore better results as the overall infiltration was underestimated in the reference simulation. In the case of lower hydraulic conductivity, it increased by $286 \%$ and therefore much stronger than with a fixed hydraulic conductivity (59\%), balancing the reduced hydraulic conductivity and resulting in a similar infiltration as with the higher hydraulic conductivity.

For the two laboratory experiments after Lima [35] (Test 2 and 3), the initial soil moisture deficit slightly increased leading to an increased infiltration, while the initial soil water content was fixed (taken from measurements from Lima [35]), meaning that effectively the saturated soil water content increased. The hydraulic conductivity was not calibrated but fixed either according to the value after Rawls et al. [54] for the given soil type (no change compared to the reference simulation) or after Lima [35] respectively, where it was $77 \%$ higher in Test 2 and $59 \%$ lower in Test 3 compared to the reference simulations. As infiltration was strongly underestimated in the reference simulation of Test 2, the capillary suction head strongly increased by $506 \%$ in the case of the same hydraulic conductivity, and still significantly increased by $242 \%$ in the case of higher hydraulic conductivity, leading to a stronger infiltration than in the reference simulation. In Test 3 , the capillary suction head also increased in both cases, while it is higher in the case of decreased hydraulic conductivity (310 $\%$ compared to $129 \%)$.

For the experiment in the Thiès catchment (Test 4), the initial soil moisture deficit slightly decreased as a result of the automatic calibration leading to less infiltration as in the reference simulation where infiltration was strongly overestimated. Using the fixed values after Innovyze [27] led to an increase of the initial soil moisture deficit by $57 \%$ compared to the reference simulation. The hydraulic conductivity was strongly reduced by $86 \%$ in the case of automatic calibration, while the lower bound of the calibration range was decreased according to the calibrated value after Simons [62]. When the fixed value of the maximum hydraulic conductivity for sand after Innovyze [27] was used, it was decreased by $90 \%$ compared to the reference simulation, therefore infiltration induced by hydraulic conductivity was reduced in both cases. Remarkably, the capillary suction head was strongly increased by $288 \%$ during calibration and by $105 \%$ with the fixed value after Innovyze [27], causing an enhanced 
capillary suction induced infiltration compared to the reference simulation. But the overall infiltration (dependent on initial soil moisture deficit, hydraulic conductivity, and capillary suction) was less than in the reference simulation and therefore led to significantly improved results represented by much higher values of NSE. The fact that for all test cases two considerably different parameter sets led to similar results and therefore similar values of NSE emphasizes again the problem of equifinality during the calibration process, which makes it difficult to give clear recommendations for the single parameters.

In the case study about flash floods in Egypt, a reduction of the hydraulic conductivity by $97 \%$ combined with an increase of the capillary suction head by $80 \%$ (corresponding to the average parameters after Rawls et al. [54] for loam), led to much more plausible results of inundation areas and water depths than with the average parameters after Rawls et al. [54] for the dominant soil type sand.

As shown in Test 4, choosing the values after Innovyze [27] considering the maximum hydraulic conductivity improved the NSE by $568 \%$ compared to the average values after Rawls et al. [54]. In Test 2 and 3, the NSE also increased by $162 \%$ and $8 \%$, respectively, when the fixed values after Innovyze [27] with the maximum hydraulic conductivity were chosen instead of the average values after Rawls et al. [54] (not represented in Fig. 15). Hence, it can be concluded that the literature values after Innovyze [27] might be generally more suitable to estimate the Green-Ampt parameters in ungauged areas than the average values after Rawls et al. [54]. In the case study about flash floods in El Gouna (see 3.5), the values for sand after Innovyze [27] under consideration of the lowest value for the hydraulic conductivity led to much more plausible results than the average values for sand after Rawls et al. [54]. As using the maximum value instead of the mean value for the hydraulic conductivity after Innovyze [27] resulted in a better performance for the Test cases 2, 3 and 4, it could be concluded to better choose the hydraulic conductivity within the upper part of the range after Innovyze [27] (according to Akan [2]). On the other hand, the results of the case study in El Gouna showed, that even when choosing the lowest value for the hydraulic conductivity after Innovyze [27] infiltration was still overestimated. Overall, according to the presented results, the values after Innovyze [27] can be rather recommended than the ones after Rawls et al. [54], while the selection of the hydraulic conductivity should be checked individually according to the plausibility of the results for each considered case.

\section{Discussion}

The result of the different test cases as well as the case study in Egypt emphasized that taking into account the average values for the Green-Ampt parameters after Rawls et al. [54] does often not lead to appropriate results. 
In the laboratory experiments after Smith and Woolhiser [64] for sandy soil and after Lima [35] for loam, the average values after Rawls et al. [54] led to a significant underestimation of infiltration, while in the field experiment in the Thiès catchment in Senegal as well as in the case study in Egypt, they strongly overestimated the infiltration, resulting in no surface runoff which is not representing the observed incidents. For the second laboratory experiment after Lima [35] for clay loam, the simulation with average Green-Ampt parameters after Rawls et al. [54] resulted in a relatively good agreement to the observations. When considering the typical values for the Green-Ampt parameters after Innovyze [27], the results for the experiment after Lima [35] for loamy soil as well as for the Thiès catchment and the case study in El Gouna for sandy soil were much better than with the average values after Rawls et al. [54]. Nevertheless, infiltration was still underestimated in the experiment after Lima [35] with loamy soil, as well as in the experiment in the Thiès catchment in Senegal, while it was still overestimated for El Gouna, even when using the minimum value for the hydraulic conductivity after Akan [2]. The consideration of a surface crust of a few millimeters generated much more plausible results for the first hours of simulation time, while the fast decrease in water depth after the flood event does not represent the real conditions appropriately. Furthermore, it was shown that the effect of friction on the infiltration process can also be significant, especially in larger-scale applications.

As the performance of average Green-Ampt parameters for sand after Rawls et al. [54] for laboratory experiments tend to go in the reverse direction than for field experiments, it could be argued that the conditions of the laboratory experiments did not represent similar conditions as occurring in the field. One reason could be that during the laboratory experiments, the formation of a crust could have been prevented due to covering the soil with gauze as described in the experimental setup of Smith and Woolhiser [64], that protected the soil surface from raindrop impact. Furthermore, it might have been the case that the soil was more homogenous so that no finer particles could lead to clogging of the pores. On the other hand, the trend to overestimate infiltration by average Green-Ampt parameters after Rawls et al. [54] under natural and field conditions was studied here only for sandy soils in semi-arid to arid areas. Case studies in areas with different soil texture classes as well as other climate conditions might lead to other results.

Prado Hernández et al. [53] investigated six different texture classes from loam to clay in Mexico and compared different approaches to estimate the Green-Ampt parameters with measured infiltration rates from double-ring infiltrometer tests. Their results show a strong underestimation of infiltration when considering the average values after Rawls et al. [54]. This observation agrees well with the results from the laboratory experiments after Smith and Woolhiser [64] as well as Lima [35] for loam, where infiltration with average values after Rawls et al. [54] was also strongly underestimated. On the other hand, ponded infiltration rates as measured 
with double-ring infiltrometers tend to be higher than the actual infiltration rates during natural or simulated rainfall events $[44,76]$. Therefore, it might be questionable to evaluate the results from the Green-Ampt model with the ponded infiltration rates from double-ring infiltrometer tests, when the aim is to estimate infiltration during rainfalls. In other studies, such as Xiang et al. [79], the Green-Ampt parameters were derived from rainfall simulator tests, where the observed infiltration probably agrees better with the one during natural rainfalls than the ponded infiltration measured from double-ring infiltrometer test.

\section{Conclusions and outlook}

A robust depth-averaged 2D shallow water model incorporating the Green-Ampt model for infiltration was used to study the performance of tabulated values for the Green-Ampt parameters taken from different sources in the literature. Four different test cases with observed data to enable an evaluation of model results as well as one real-world application in an ungauged area were investigated, where average values for different soil texture classes after Rawls et al. [54] on the one hand and after Innovyze [27] on the other hand resulted in different performances. The average values after Rawls et al. [54] led to underestimations of infiltration in laboratory experiments with sandy and loamy soil, respectively, while showing a relatively good agreement in a laboratory experiment with clay loam, and strongly overestimated infiltration in a field experiment in Senegal as well as in a case study in Egypt, both with almost bare sandy soil. For the laboratory experiment with loam, the field experiment in Senegal and the case study in Egypt, the values after Innovyze [27] resulted in better performances than the ones after Rawls et al. [54], while they strongly underestimated infiltration in the laboratory experiment after Smith and Woolhiser [64], still underestimated the infiltration for the experiment with loam, and also for the field experiment in Senegal, and overestimated the infiltration in the case study in Egypt. Based on the obtained results for the two cases in real catchments with sandy soil (Test 4 in Thiès catchment, Senegal and the Case study El Gouna, Egypt), it is recommended to use lower values for the hydraulic conductivity than the values for sand given in Rawls et al. [54] to prevent an overestimation of infiltration. In both cases, the hydraulic conductivity was decreased by about $90-100 \%$, while the capillary suction head at the wetted front was increased by about $80-288 \%$ compared to the average values after Rawls et al. [54]. Despite of this strong increase of the capillary suction, which enhances infiltration particularly at early time steps when the soil moisture deficit is high, the overall infiltration rates are much smaller and more realistic than the ones with average values. This emphasizes the stronger sensitivity of surface runoff on the hydraulic conductivity than on the capillary suction.

Overall, it can be recommended to use the values after Innovyze [27] rather than the average values after Rawls et al. [54] as they led to better results in all studied cases except for the laboratory after Smith and 
Woolhiser [64] (Test case 1). If the given soil of the considered study area might tend to form a surface crust during heavy rainfalls, as it is for example the case for bare soils in arid areas, a thin layer of a few millimeters with reduced hydraulic conductivity to account for this crust and the application of an effective hydraulic conductivity between the crust and subcrust soil, might be suitable to represent the infiltration behavior more realistically. But in the represented results, this approach also led to an overestimation of infiltration at later times steps if the parameter values of the subcrust soil are taken from Rawls et al. [54]. As for both cases in natural areas (in Senegal and Egypt) the soil texture class was sand, further investigations should be carried out for field tests with other soil texture classes to give recommendations also for ungauged areas with other dominant soil texture classes

For the case study in Egypt, it is planned to carry out rainfall simulator tests to get a better estimation of the infiltration behavior occurring during natural rainfall events in that area. Through measuring the surface runoff and soil moistures, as well as recording the plot areas with digital photos to generate high-resolution DEMs using photogrammetry, the plot-scale field tests can be simulated and calibrated afterwards to derive appropriate Green-Ampt parameters for the model area. Furthermore, the possibly occurring surface sealing as well as microtopography and their effect on infiltration will be studied, in addition to the influence of the DEM resolution on modeling infiltration. The overall aim is to define the most important determinants that influence infiltration under different circumstances and to find suitable values of Green-Ampt parameters for different cases.

\section{Declarations}

Funding: This work was supported by the Technische Universität Berlin and the DFG Research Training Group "UrbanWater Interfaces" (GRK 2032/2).

Conflicts of interest/Competing interests: On behalf of all authors, the corresponding author states that there is no conflict of interest.

Availability of data and material: Data and material can be provided on request.

Code availability: The full source code of $\mathrm{hms}$ is available at https://gitlab.tu-berlin.de/hms. Access to the GIT repository is granted by the Chair of Water Resources Management and Modeling of Hydrosystems, Technische Universität Berlin, Germany and Modeling of Hydrosystems, Technische Universität Berlin, Germany. 
Authors' contributions: F. Tügel and R. Hinkelmann designed the framework for the publication. F. Tügel performed the computations and analyzed the results. Furthermore, she collected the data of the experiments from the literature. A. Hassan supported the calibration process by using optimization methods and developed the code for the automatic calibration. F. Tügel wrote the manuscript with support from R. Hinkelmann and J. Hou. All authors discussed the results and contributed to the final manuscript.

Acknowledgements: The simulations have been partially carried out on the supercomputers from the HPCcluster of TU Berlin and partially on the supercomputers of HLRN (Norddeutscher Verbund für Hoch- und Höchstleistungsrechnen).

\section{References}

[1] Abderrezzak KE, Paquier A, Mignot E (2009) Modelling flash flood propagation in urban areas using a twodimensional numerical model. Nat Hazards 50:433-460.

[2] Akan, AO (1993) Urban stormwater hydrology: A guide to engineering calculations.Technomic Pub. Co, Lancaster, Pennsylvania, USA

[3] Assouline S, Mualem Y (2006) Runoff from heterogeneous small bare catchments during soil surface sealing, Water Resour Res 42, W12405, https://doi.org/10.1029/2005WR004592

[4] Brakensiek DL, Rawls WJ (1983) Agricultural management effects on soil water processes. Part II: Green and Ampt parameters for crusting soils. Trans ASAE 26(6):1753-1757.

[5] Broich K, Pflugbeil T, Disse M, Nguyen H (2020) Using TELEMAC-2D for Hydrodynamic Modeling of RainfallRunoff. Zenodo, Toulouse, http://doi.org/10.5281/zenodo.3611524

[6] Caviedes-Voullième D, Murillo J, Garcia-Navarro P (2012) Influence of mesh structure on 2D full shallow water equations and SCS Curve Number simulation of rainfall/runoff events. J Hydrol 448-449:39-59.

[7] Chen L, Xiang L, Young MH, Yin J, Yu Z, Genuchten M (2015) Optimal parameters for the Green-Ampt infiltration model under rainfall conditions. J Hydrol Hydromec 63(2):93-101, https://doi.org/10.1515/johh-2015$\underline{0012}$

[8] Clapp R B, Hornberger GM (1978) Empirical equations for some soil hydraulic properties, Water Resour Res 14(4):601-604, https://doi.org/10.1029/WR014i004p00601

[9] Cui Y, Liang Q, Wang G, Zhao J, Hu J, Wang Y, Xia X (2019) Simulation of Hydraulic Structures in 2D HighResolution Urban Flood Modeling. Water 11(10), 2139, https://doi.org/10.3390/w11102139

[10] Delfs JO, Park CH, Kolditz O (2009) A sensitivity analysis of Hortonian flow. Adv Water Resour 32(9):13861395, https://doi.org/10.1016/j.advwatres.2009.06.005.

[11] Endres SC, Sandrock C, Focke WW (2018) A simplicial homology algorithm for Lipschitz optimisation. J Glob Optim 72:181-217, https://doi.org/10.1007/s10898-018-0645-y

[12] Engman ET (1986) Roughness Coefficients for Routing Surface Runoff. J Irrig Drain Eng 11(1):39-53, https://doi.org/10.1061/(ASCE)0733-9437(1986)112:1(39)

[13] Eric M, Fan C, Joksimovic D, Li JY (2013) Modeling low impact development potential with hydrological response units. Water Sci Technol 68(11):2382-2390, https://doi.org/10.2166/wst.2013.502

[14] Esteves M, Faucher X, Galle S, Vauclin M (2000) Overland Flow and Infiltration Modelling for Small Plots during Unsteady Rain: Numerical Results versus Observed Values. J Hydrol 228 (3-4):265-282, https://doi.org/10.1016/S0022-1694(00)00155-4.

[15] FAO (2019) Harmonized World Soil Database V 1.2. URL: http://www.fao.org/soils-portal/soil-survey/soilmaps-and-databases/harmonized-world-soil-database-v12/en/ 


\section{Accessed 17 Jan 2019}

[16] Farthing MW, Ogden FL (2017) Numerical Solution of Richards' Equation: A Review of Advances and Challenges. Soil Sci Soc Am J 81:1257-1269.

[17] Fernández-Pato J, Caviedes-Voullième D, García-Navarro P (2016) Rainfall/runoff simulation with 2D full shallow water equations: Sensitivity analysis and calibration of infiltration parameters. J Hydrol 536:496-513, https://doi.org/10.1016/j.jhydrol.2016.03.021.

[18] Fernández-Pato J, Gracia J L, García-Navarro P (2018) A fractional-order infiltration model to improve the simulation of rainfall/runoff in combination with a 2D shallow water model. J Hydroinformatics 20 (4):898-916, https://doi.org/10.2166/hydro.2018.145

[19] Fiedler FR, Ramirez JA (2000) A numerical method for simulating discontinuous shallow flow over an infiltrating surface. Int $J$ Numer Meth Fluids 32:219-239, https://doi.org/10.1002/(SICl)10970363(20000130)32:2<219::AID-FLD936>3.0.CO;2-J

[20] Ghazal A (2018) Urban Flood Protection in Arid Regions King Fahd Suburb in Dammam - Saudi Arabia. Master's thesis, TU Berlin Campus El Gouna, Water Engineering

[21] Green WH, Ampt GA (1911) Studies on Soil Physics, Part 1, the Flow of Air and Water through Soils. J Agric Sci 4 :11-24.

[22] Hadidi A (2016) Wadi Bili catchment in the eastern desert-flash floods, geological model and hydrogeology. Berlin: Fakultät VI - Planen Bauen Umwelt der Technischen Universität Berlin.

[23] Hassan A, Özgen I, Hinkelmann R (2018) Using a simplex-type optimization method to calibrate a hydrodynamic model for rainfall-runoff simulations. Proceedings of the 5th IAHR (International Association of Hydro-Environment Engineering and Research) Europe Congress - New Challenges in Hydraulic Research and Engineering, 12 - 14 June, 2018. ISBN: 978-981-11-2731-1

[24] Hallouin T (2019) HydroEval: Streamflow Simulations Evaluator (Version 0.0.3). Zenodo. https://doi.org/10.5281/zenodo.2591217

[25] Hendrickx JM, Walker G (1997) Recharge from Precipitation, Chapter 2. In: Simmers, I., Ed., Recharge of Phreatic Aquifers in (Semi)-Arid Areas, IAH Contributions to Hydrogeology Series, Taylor and Francis, Balkema, Rotterdam.

[26] Huang W, Cao Z, Huang M, Duan W, Ni Y, Yang W (2019) A New Flash Flood Warning Scheme Based on Hydrodynamic Modelling. Water 11(6), 1221, https://doi.org/10.3390/w11061221

[27] Innovyze (2019) Help documentation of XPSWMM and XPStorm. https://help.innovyze.com/display/xps/Infiltration

Accessed 30 Apr 2020

[28] Jain MK, Kothyari UC, Ranga Raju KG (2004) A GIS distributed rainfall-runoff model. J Hydrol 299:107-135.

[29] JAXA (2017) ALOS Global Digital Surface Model "ALOS World 3D-30 m (AW3D30). Japan Aerospace Exploration Agency Earth Observation Research Center http://www.eorc.jaxa.jp/ALOS/en/aw3d30/index.htm Accessed 20 Feb 2017

[30] Klove B, Ala-Aho P, Bertrand G, Gurdak JJ, Kupfersberger H, Kværner, J, Muotka T (2014) Climate Change Impacts on Groundwater and Dependent Ecosystems. J Hydrol 518(Part B):250-266, https://doi.org/10.1016/j.jhydrol.2013.06.037

[31] Kong F, Ban Y, Yin H, James P, Dronova I (2017) Modeling stormwater management at the city district level in response to changes in land use and low impact development. Environ Model Softw 95:132-142, https://doi.org/10.1016/j.envsoft.2017.06.021

[32] Leandro J, Schumann A, Pfister A (2016) A step towards considering the spatial heterogeneity of urban key features in urban hydrology flood modelling. J Hydrol 535:356-365.

[33] Liang Q, Du G, Hall JW, Borthwick AG (2008) Flood Inundation Modeling with an Adaptive Quadtree Grid Shallow Water Equation Solver. J Hydraul Eng 134(11):1603-1610, https://doi.org/10.1061/(ASCE)07339429(2008)134:11(1603)

[34] Liang Q, Xia X, Hou J (2016) Catchment-scale high-resolution flash flood simulation using the GPU-based technology. Procedia Eng 154:975-981, https://doi.org/10.1016/i.proeng.2016.07.585. 
[35] Lima JLMP (1989) Overland flow under rainfall: some aspects related to modelling and conditioning factores. $\mathrm{PhD}$ thesis. Agricultural University Wageningen, The Netherlands. https://library.wur.nl/WebQuery/wurpubs/fulltext/202869

Accessed 30 Apr 2020

[36] Mallari KJB, Kim H, Pak G, Aksoy H, Yoon J (2015) A comparison of two infiltration models applied to simulation of overland flow over a two-dimensional flume. Water Sci Technol 71 (9):1325-1332, https://doi.org/10.2166/wst.2015.060

[37] McIntyre DS (1958) Permeability measurements of soil crusts formed by raindrop impact. Soil Sci 85(4): 185189

[38] Mein RG, Larson CL (1971) Modeling the Infiltration Component of the Rainfall-Runoff Process.: Water Resources Research Center, Minneapolis, Minnesota, USA

[39] Miller J D, Hutchins M (2017) The impacts of urbanisation and climate change on urban flooding and urban water quality: A review of the evidence concerning the United Kingdom. J Hydrol: Regional Studies 12:345-362, https://doi.org/10.1016/j.ejrh.2017.06.006

[40] Mohammadzadeh-Habili J, Heidarpour M (2015) Application of the Green-Ampt model for infiltration into layered soils. J Hydrol 527:824-832, https://doi.org/10.1016/i.jhydrol.2015.05.052

[41] Morin J, Benyamini Y (1977) Rainfall infiltration into bare soils, Water Resour Res 13( 5):813-817, https://doi.org/10.1029/WR013i005p00813

[42] Mu W, Yu F, Li C, Xie Y, Tian J, Liu J, Zhao N (2015) Effects of Rainfall Intensity and Slope Gradient on Runoff and Soil Moisture Content on Different Growing Stages of Spring Maize. Water 7:2990-3008.

[43] Mügler C, Planchon O, Patin J, Weill S, Silvera N, Richard P, Mouche E (2011) Comparison of roughness models to simulate overland flow and tracer transport experiments under simulated rainfall at plot scale. $\mathrm{J} \mathrm{Hydrol}$ 402:25-40.

[44] Müller EN (2007) Scaling approaches to the modelling of water, sediment and nutrient fluxes within semiarid landscapes, Jornada Basin. New Mexico, Logos Verlag Berlin, ISBN 978-3-8325-1754-0, PhD thesis submitted 2004 to King's College London, UK.

[45] Nciizah AD, Wakindiki IIC (2015) Soil sealing and crusting effects on infiltration rate: a critical review of shortfalls in prediction models and solutions, Arch Agron Soil Sci 61(9): 1211-1230, https://doi.org/10.1080/03650340.2014.998203

[46] Nash JE, Sutcliffe JV (1970) River flow forecasting through conceptual models part I - A discussion of principles. J Hydrol 10(3):282-290, https://doi.org/10.1016/0022-1694(70)90255-6

[47] Nassif SH, Wilson EM (1975) The influence of slope and rain intensity on runoff and infiltration. Hydrol Sci Bull 20(4):539-553, https://doi.org/10.1080/02626667509491586

[48] Ni,Y, Cao Z, Liu Q, Liu Q (2020) A 2D hydrodynamic model for shallow water flows with significant infiltration losses. Hydrol Process 34:2263-2280, https://doi.org/10.1002/hyp.13722

[49] Özgen I, Simons F, Zhao J, Hinkelmann R (2014) Modeling Shallow Water Flow And Transport Processes With Small Water Depths Using The Hydroinformatics Modelling System. New York: CUNY Academic Works.

[50] Palla A, Gnecco I (2015) Hydrologic modeling of Low Impact Development systems at the urban catchment scale. J Hydrol 528:361-368, https://doi.org/10.1016/i.jhydrol.2015.06.050.

[51] Park S, Kim B, Kim DH (2019) 2D GPU-Accelerated High Resolution Numerical Scheme for Solving Diffusive Wave Equations. Water 11, 1447

[52] Pool S, Vis M, Seibert J (2018) Evaluating model performance: towards a non-parametric variant of the KlingGupta efficiency. Hydrol Sci J 63(13-14):1941-1953, https://doi.org/10.1080/02626667.2018.1552002

[53] Prado Hernández JV, Pascual Ramírez F, Cristóbal Acevedo D, Carrillo García M., Martínez Ruíz A (2016) Determination and Evaluation of the Parameters for the Green \& Ampt Infiltration Equation in Some Agricultural Soils in Mexico. Preprints 2016, 2016120067, https://doi.org/10.20944/preprints201612.0067.v1

[54] Rawls WJ, Brakensiek DL, Miller N (1983) Green-Ampt Infiltration Parameters from Soils Data. J Hydraul Eng 1:62-70, https://doi.org/10.1061/(ASCE)0733-9429(1983)109:1(62) 
[55] Rawls WJ, Brakensiek DL (1989) Estimation of soil water retention and hydraulic properties. In: MorelSeytoux HJ (ed) Unsaturated Flow in Hydrologic Modeling - Theory and Practice. Springer, Dordrecht, pp 275300.

[56] Rawls WJ, Brakensiek DL, Simanton JR, Kohl KD (1990) Development of a Crust Factor for a Green Ampt Model. Trans ASAE 33 (4):1224-1228, https://doi.org/10.13031/2013.31461

[57] Ribolzi O, Patin J, Bresson LM, Latsachack K, Mouche E, Sengtaheuanghoung O, Silvera N, Thiébaux J, Valentin C (2011) Impact of slope gradient on soil surface features and infiltration on steep slopes in northern Laos. Geomorphology 127:53-63.

[58] Ries F, Kirn L, Weiler M (2020) Experimentelle Untersuchung der Abflussbildung bei Starkregen - Hydrol. und Wasserbewirtschaftung 64(5):221-236, https://doi.org/10.5675/HyWa 2020.51

[59] Roland A, Rausch R, Huxhorn T, Kraus T, Wallisch S, Sikiric MD, Zhang YJ, Zanke U (2015) Hochauflösende Simulation von urbanen Sturzfluten Anwendungsbeispiel: Überflutungsprüfung für die Stadt Worms. Korrespondenz Abwasser, Abfall 62(3):215 - 224

[60] Schaap MG, Leij FJ, van Genuchten MT (2001) Rosetta: a computer program for estimating soil hydraulic parameters with hierarchical pedotransfer functions. J Hydrol 251:163-176.

[61] Sharma ML, Gander GA, Hunt CG (1980) Spatial variability of infiltration in a watershed. J Hydrol 45(12):101-122, https://doi.org/10.1016/0022-1694(80)90008-6

[62] Simons F (2020) A robust high-resolution hydrodynamic numerical model for surface water flow and transport processes within a flexible software framework. PhD thesis, Technische Universität Berlin, Germany. https://henry.baw.de/bitstream/handle/20.500.11970/107124/simons franz.pdf?sequence=1\&isAllowed=y

Accessed 30 Apr 2020

[63] Simons F, Busse T, Hou J, Özgen I, Hinkelmann R (2014) A Model for overland flow and associated processes within the Hydroinformatics Modelling System. J Hydroinformatics 16(2):375-391. https://doi.org/10.2166/hydro.2013.173

[64] Smith RE, Woolhiser DA (1971) Overland flow on an infiltrating surface. Water Resour Res 7(4):899-913.

[65] Tackett JL, Pearson RW (1965) Soil Sci 99(6):407-413

[66] Tatard L, Planchon O, Wainwright J, Nord G, Favis-Mortlock D, Silvera N, Ribolzi O, Esteves M, Chi Hua Huang (2008) Measurement and modelling of high-resolution flow-velocity data under simulated rainfall on a lowslope sandy soil. J Hydrol 348(1-2):1-12, https://doi.org/10.1016/j.jhydrol.2007.07.016

[67] Twarakavi, NKC, Šimůnek J, Schaap MG (2010) Can texture-based classification optimally classify soils with respect to soil hydraulics? Water Resour Res, 46, W01501, doi:10.1029/2009WR007939

[68] Thompson SE, Katul GG, Porporato A ( 2010) Role of microtopography in rainfall-runoff partitioning: An analysis using idealized geometry, Water Resour Res 46, W07520, https://doi.org/10.1029/2009WR008835

[69] Tügel F, Özgen-Xian I, Marafini E, Hadidi A, Hinkelmann R (2020a) Flash flood simulations for an Egyptian city - mitigation measures and impact of infiltration. Urban Water $J$ 17(5):396-406, https://doi.org/10.1080/1573062X.2020.1713171

[70] Tügel F, Abdelrahman AAA, Özgen-Xian I, Hadidi A, Hinkelmann R (2020b) Rainfall-runoff modeling to investigate flash floods and mitigation measures in the Wadi Bili catchment, Egypt. In: Gourbesville P., Caignaert G. (eds) Advances in Hydroinformatics. Springer Water. Springer, Singapore. https://doi.org/10.1007/978-98115-5436-0 44

[71] Turner ER (2006) Comparison of infiltration equations and their field validation with rainfall simulation. M.sc Thesis, Department of Biological Resources Engineering, Faculty of the Graduate School of the University of Maryland, College Park.

[72] Van den Putte A, Govers G, Leys A, Langhans C, Clymans W, Diels J (2013) Estimating the parameters of the Green-Ampt infiltration equation from rainfall simulation data: Why simpler is better, $J$ Hydrol 476: 332-344, https://doi.org/10.1016/j.jhydrol.2012.10.051.

[73] Van Mullem JA (1989) Applications of the Green-Ampt infiltration model to watersheds in Montana and Wyoming. Montana State University.

[74] Vergroesen T, Verschelling E, Becker B (2014) Modelling of sustainable urban drainage measures. Revista de Ingeniería Innova 8:1 - 16 
[75] Viero DP, Peruzzo P, Carniello L, Defina A (2014) Integrated mathematical modeling of hydrological and hydrodynamic response to rainfall events in rural lowland catchments. Water Resour Res 50:5941-5957, https://doi.org/10.1002/2013WR014293

[76] Wainwright J (1996) Infiltration, runoff and erosion characteristics of agricultural land in extreme storm events, SE France. Catena 26(1-2):27-47, https://doi.org/10.1016/0341-8162(95)00033-X

[77] Wannous M, Theilen-Willige B, Troeger U, Falk M, Bauer F (2021) Hydrochemistry and environmental isotopes of spring water and their relation to structure and lithology identified with remote sensing methods in Wadi Araba, Egypt. Submitted to Hydrogeology J.

[78] Whisler F, Bouwer H (1970) Comparison of methods for calculating vertical drainage and infiltration for soils. J Hydrol 1:1-19, https://doi.org/10.1016/0022-1694(70)90051-X

[79] Xiang L, Ling W, Zhu Y, Chen L, Yu Z (2016) Self-adaptive Green-Ampt infiltration parameters obtained from measured moisture processes. Water Sci Eng 9(3):256-264, https://doi.org/10.1016/j.wse.2016.05.001.

[80] Xing Y, Liang Q, Wang, G, Ming, X, Xia, X (2019) City-scale hydrodynamic modelling of urban flash floods: the issues of scale and resolution. Nat Hazards 96:473-496, https://doi.org/10.1007/s11069-018-3553-z 


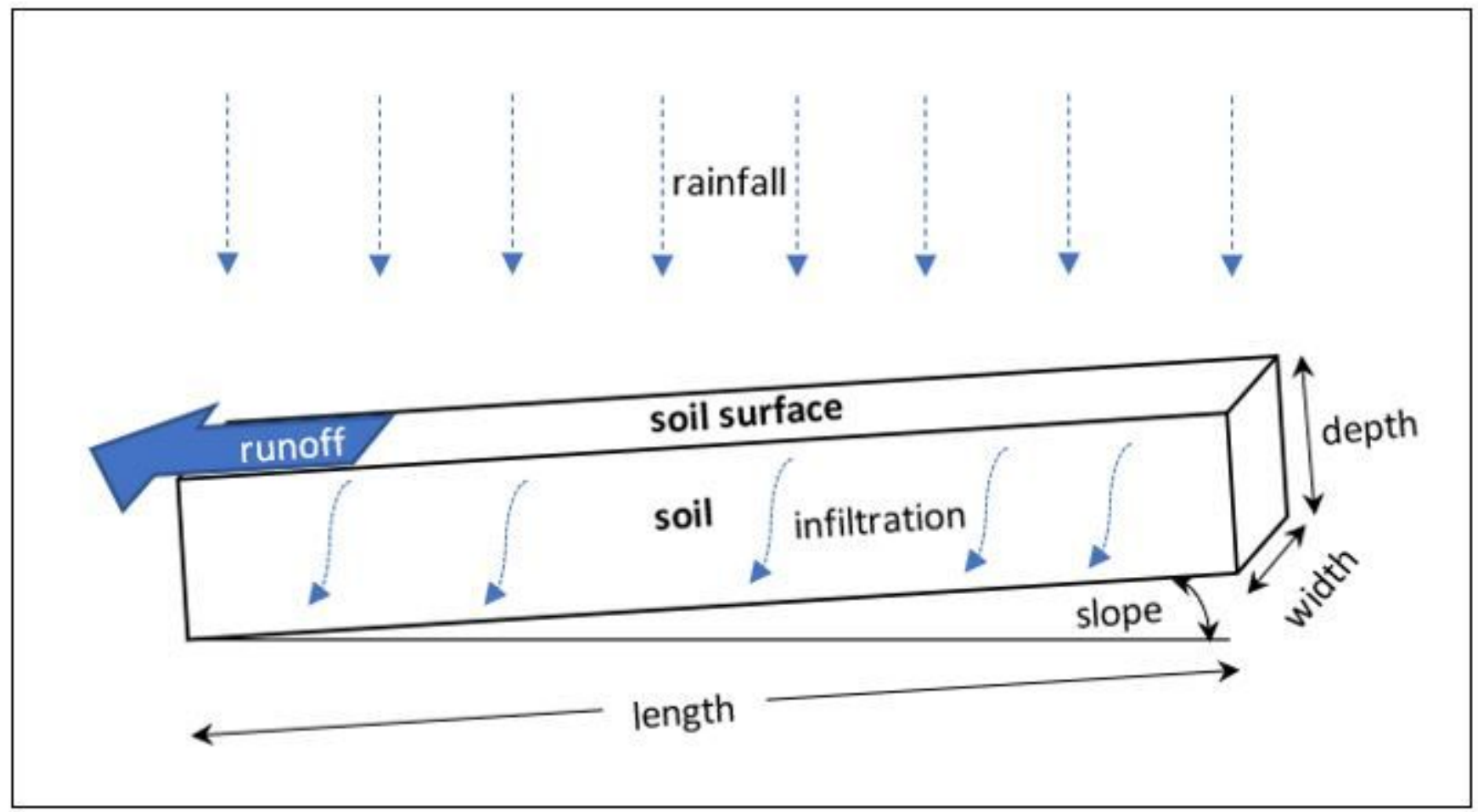

Figure 1

Sketch of soil flume of the laboratory experiments in Test cases 1, 2 and 3
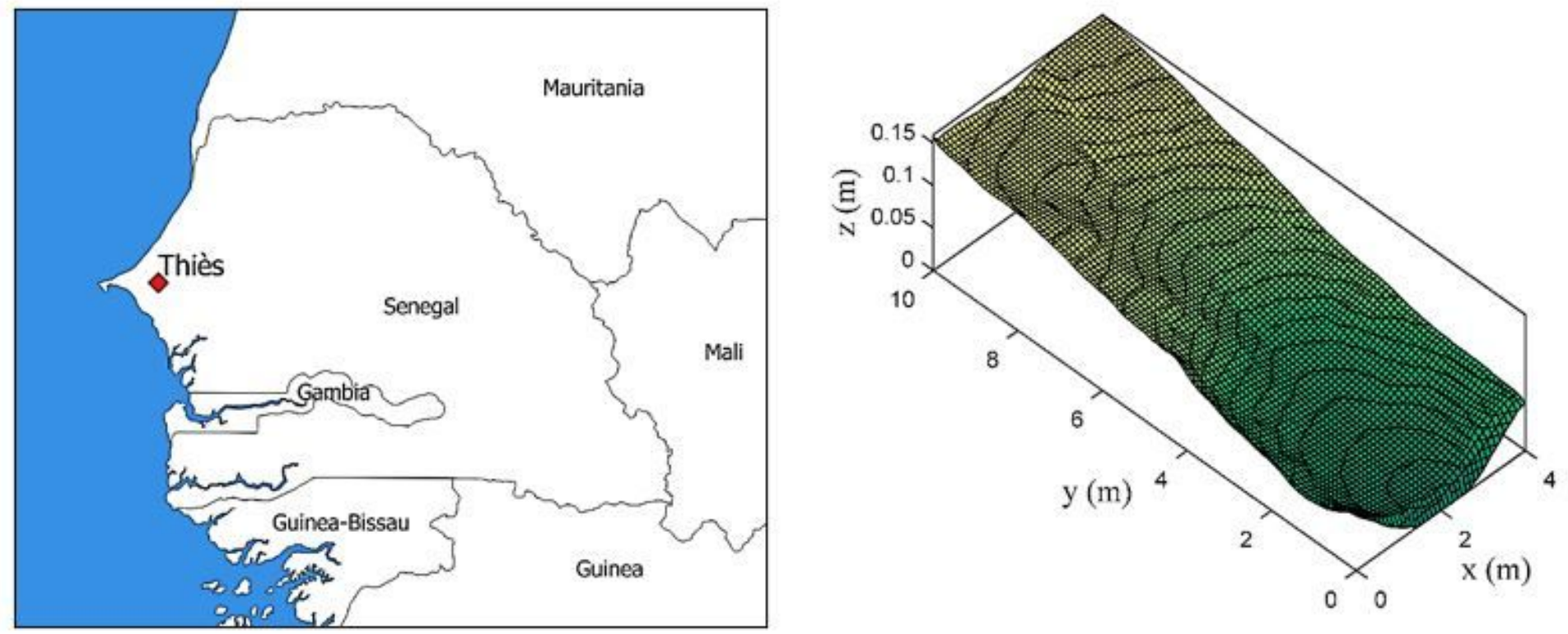

Figure 2

Left: Location of the Thiès catchment in Senegal (made with Natural Earth), right: elevation of the tested basin [51] 


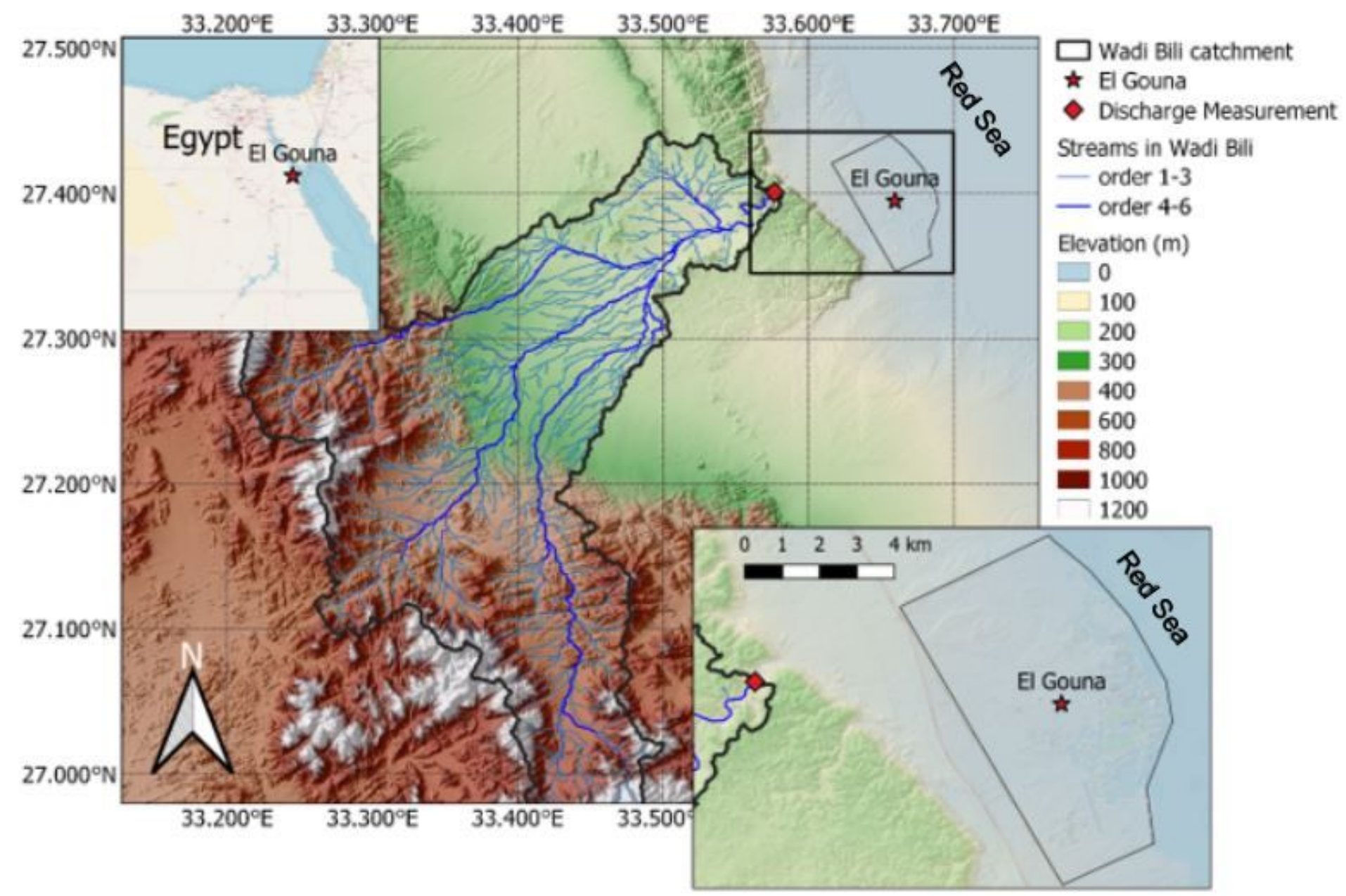

\section{Figure 3}

Location of El Gouna and the Wadi Bili catchment in Egypt, topography (AW3D30 @ Jaxa), and streams in the Wadi Bili catchment and model domain for the area of El Gouna as well as the location of discharge measurements in 2014 published in Hadidi [22] (map: @ OpenStreetMap contributors) 


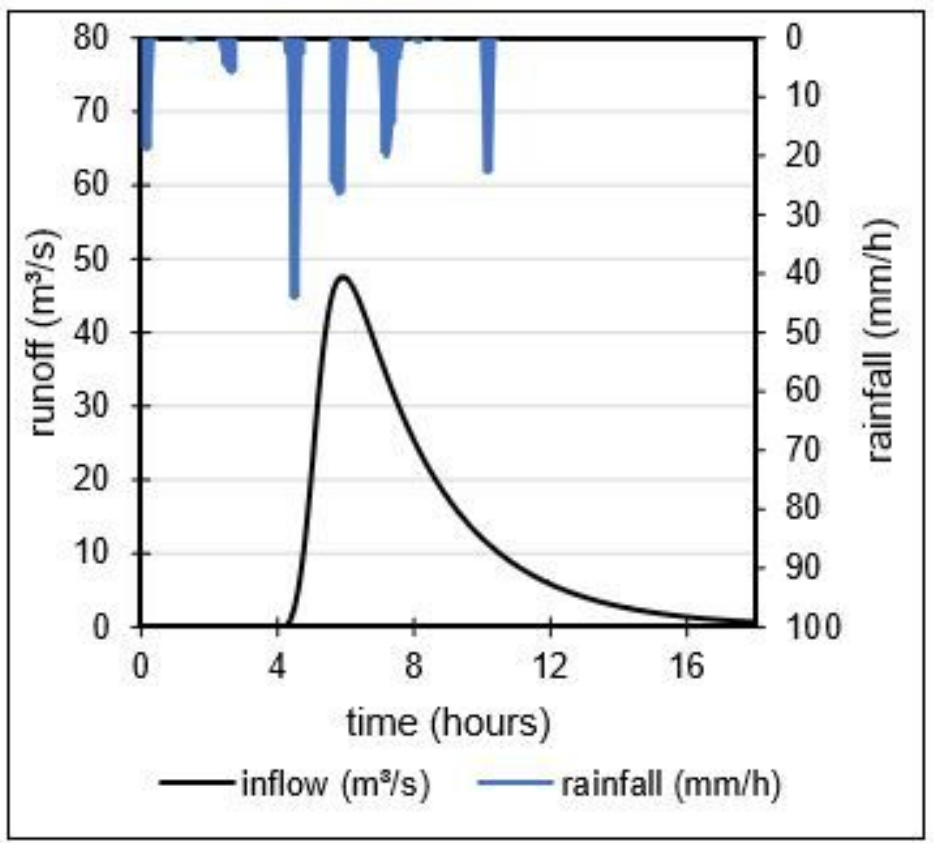

\section{Figure 4}

Rainfall and inflow imposed as source and boundary condition in the model, respectively

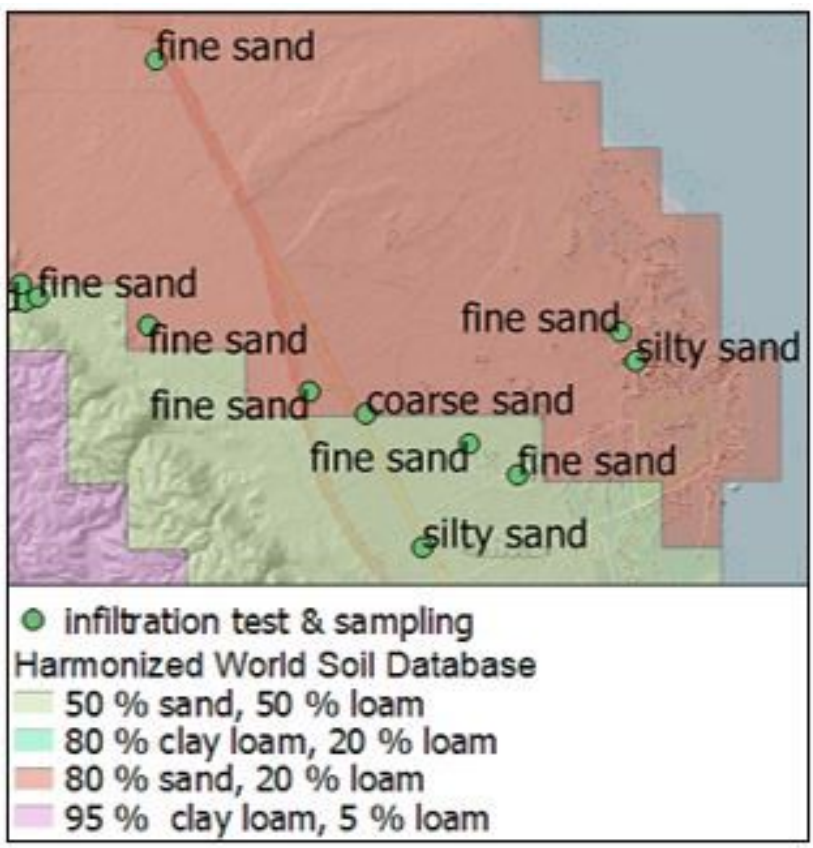

Figure 5

Soil texture classes according to the Harmonized World Soil Database and determined from double-ring infiltrometer tests 


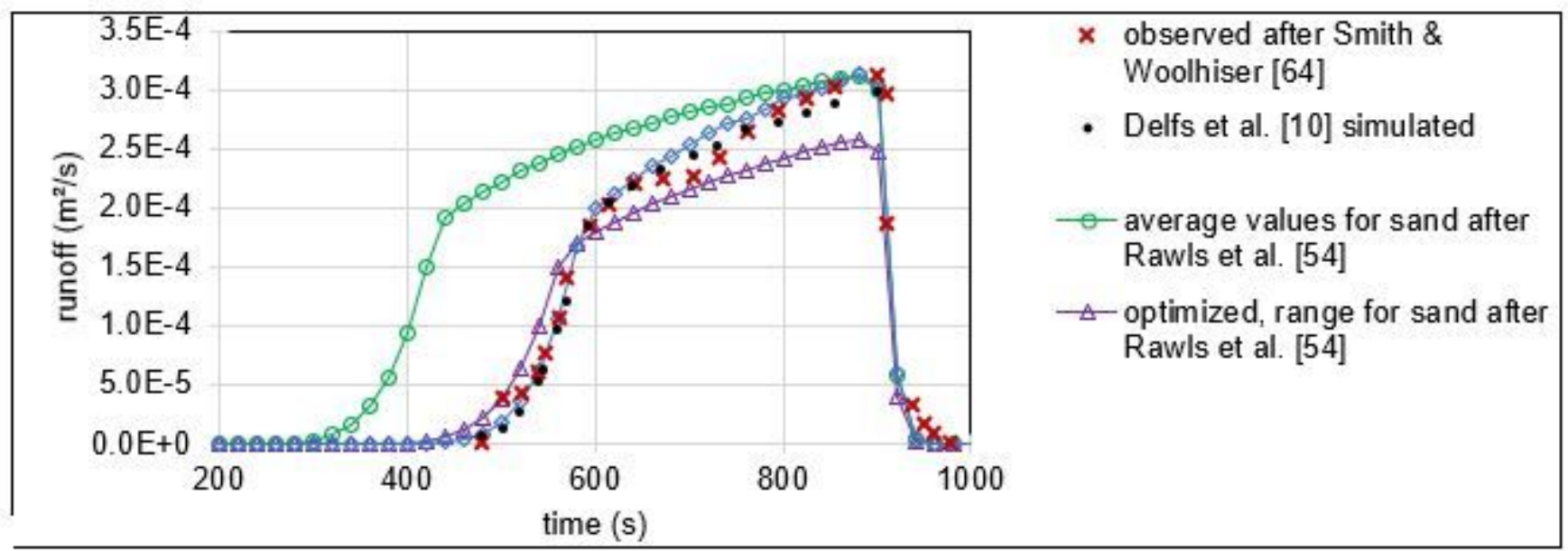

Figure 6

Different simulated runoff hydrographs for for the laboratory experiment after Smith and Woolhiser [64]

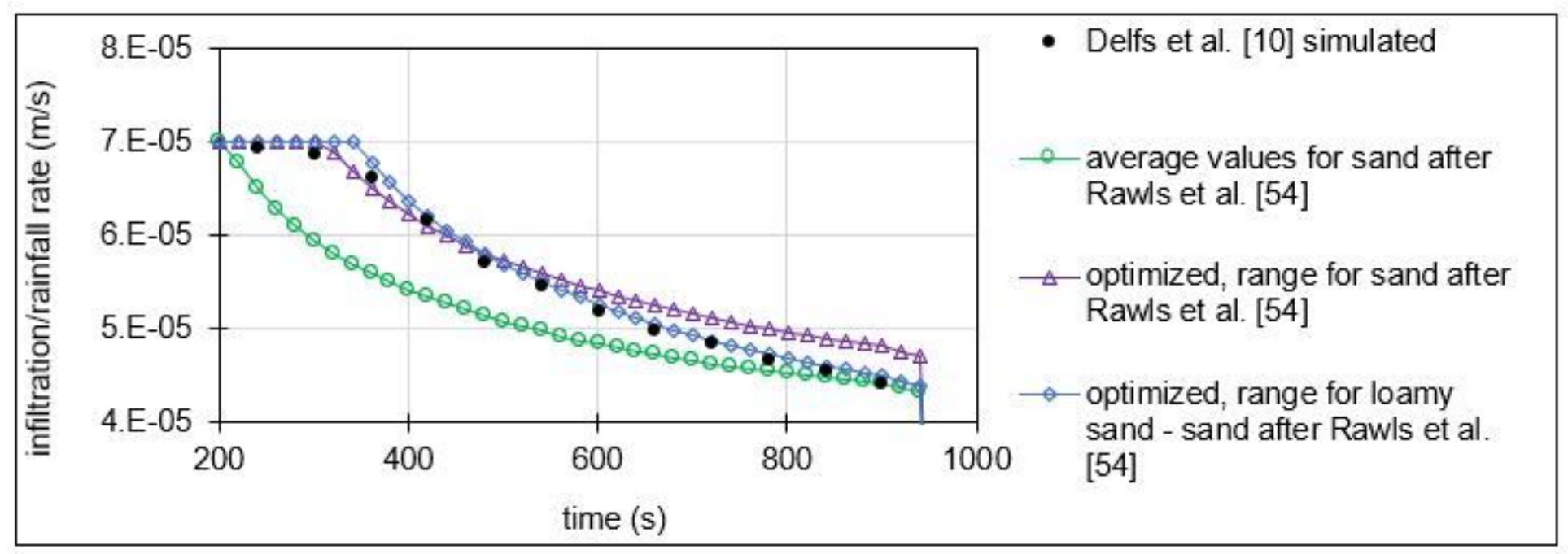

Figure 7

Infiltration rates over time for different simulations of the experiment after Smith and Woolhiser [64] 


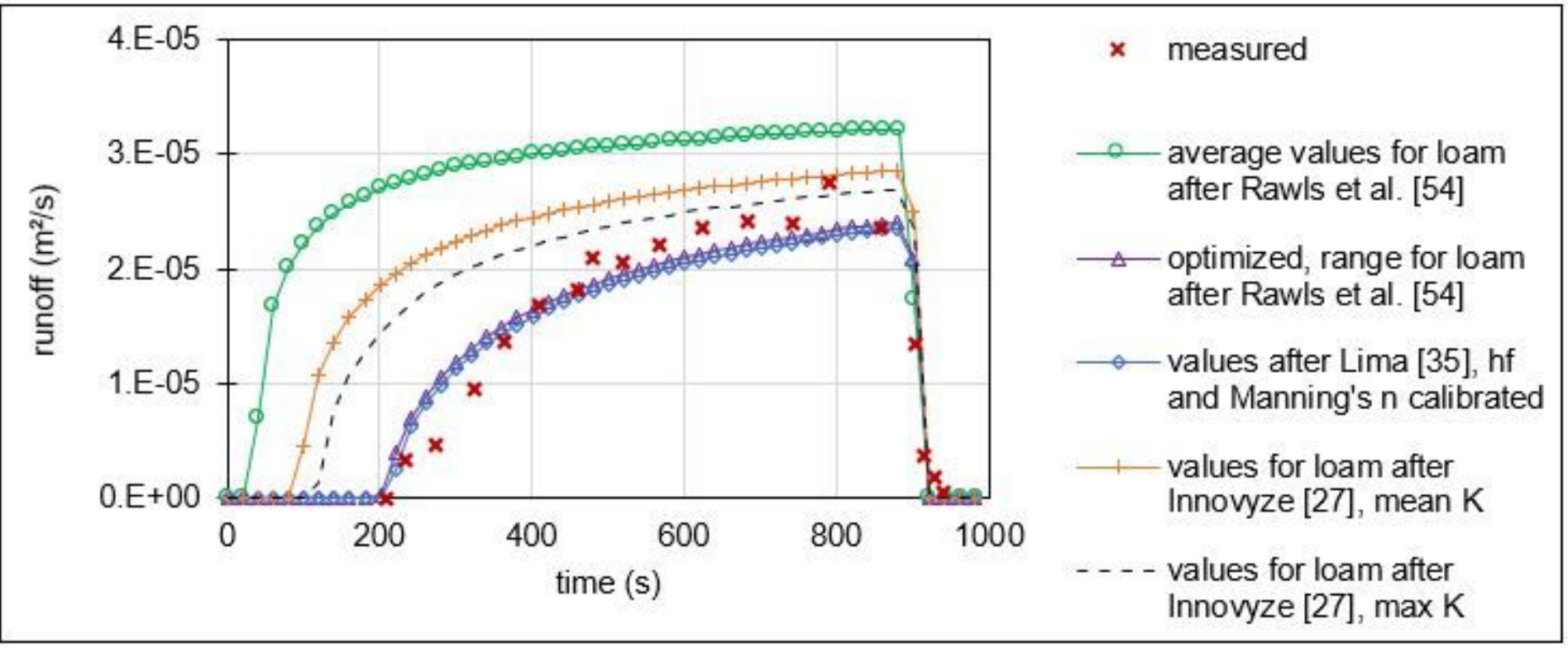

Figure 8

Runoff hydrographs for different simulations of the experiment for loamy soil after Lima [35]

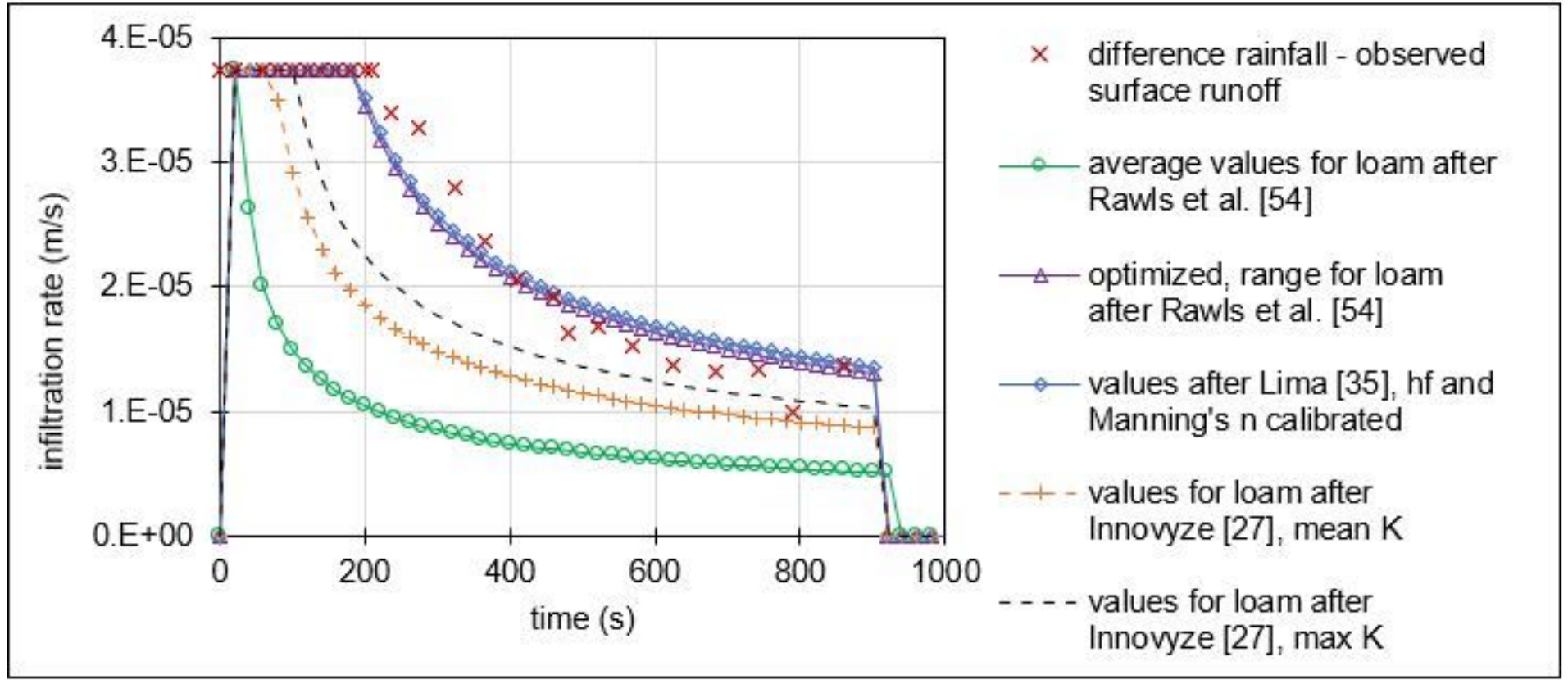

\section{Figure 9}

Infiltration rates over time for different simulations of the experiment for loamy soil after Lima [35] 


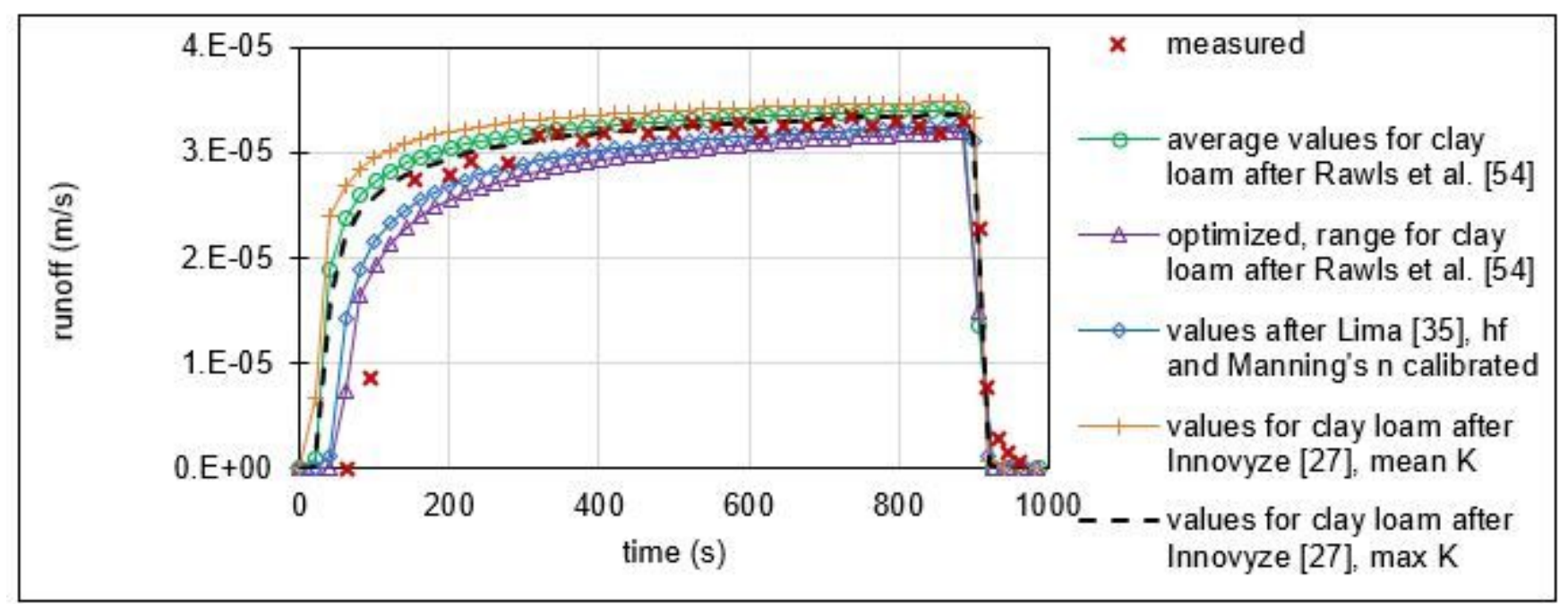

Figure 10

Runoff hydrographs for different simulations of the experiment after Lima for clay loam [35]

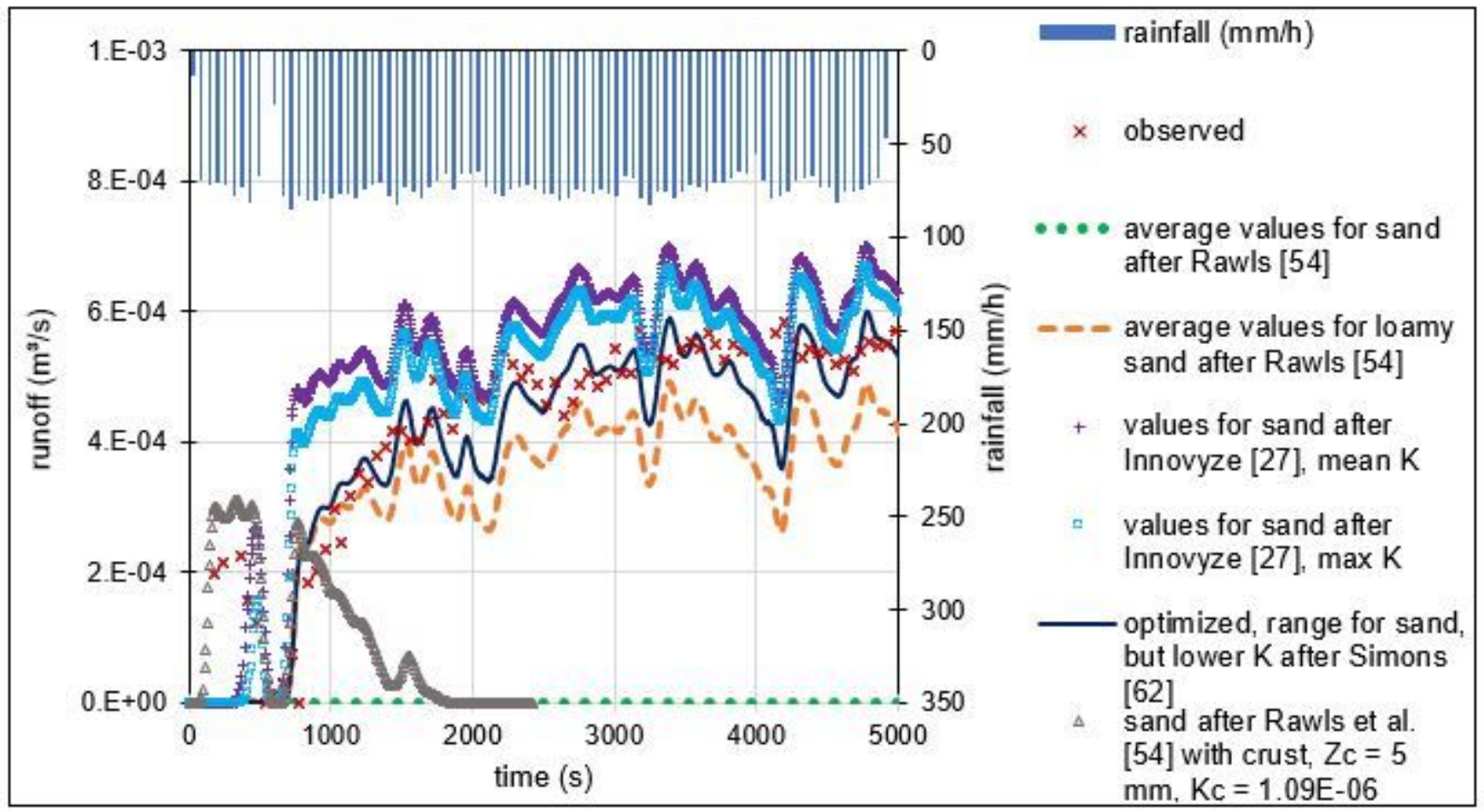

Figure 11

Runoff hydrographs for different simulations of the rainfall-runoff experiment in the Thiès catchment in Senegal 
sand with crust, $\mathrm{Zc}=5 \mathrm{~mm}, \mathrm{Kc}=\mathrm{Kclay}, \mathrm{n}=0.01 \mathrm{sm}^{-1 / 3}$

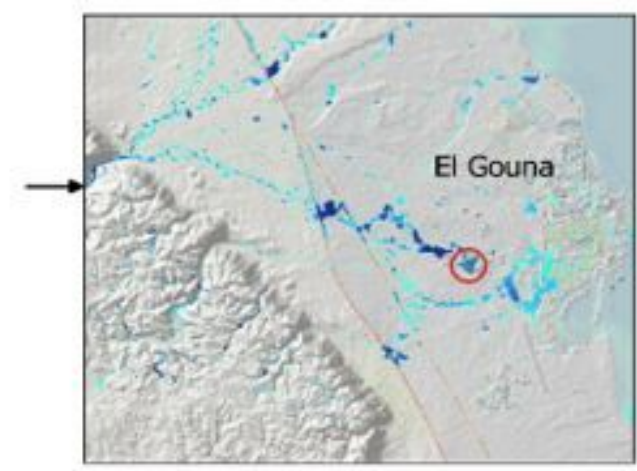

sand with crust, $\mathrm{Zc}=5 \mathrm{~mm}, \mathrm{Kc}=\mathrm{Kclay}, \mathrm{n}=0.02 \mathrm{sm}^{-1 / 3}$

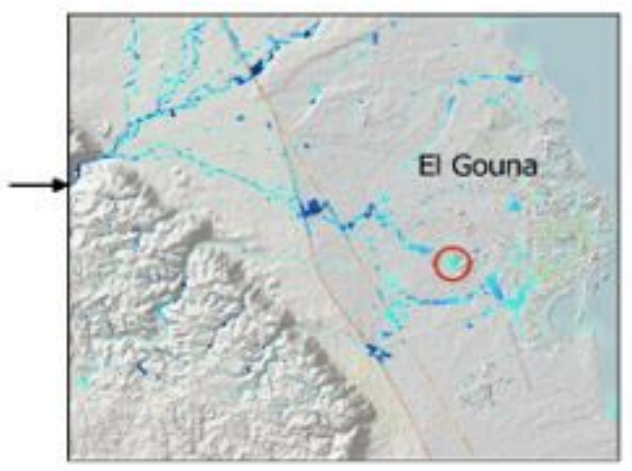

loam, $\mathrm{n}=0.01 \mathrm{sm}^{-1 / 3}$

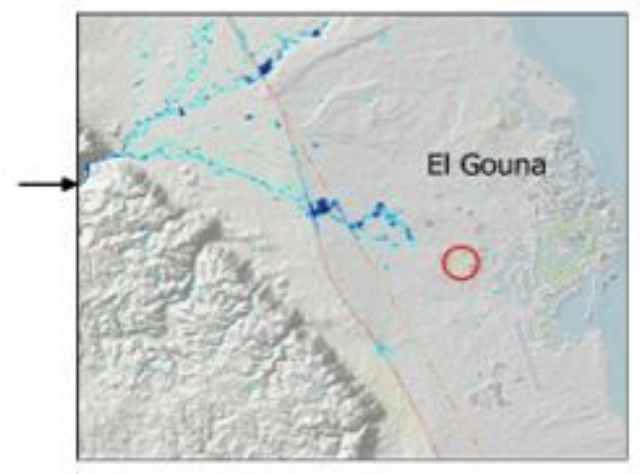

loam, $\mathrm{n}=0.02 \mathrm{sm}^{-1 / 3}$

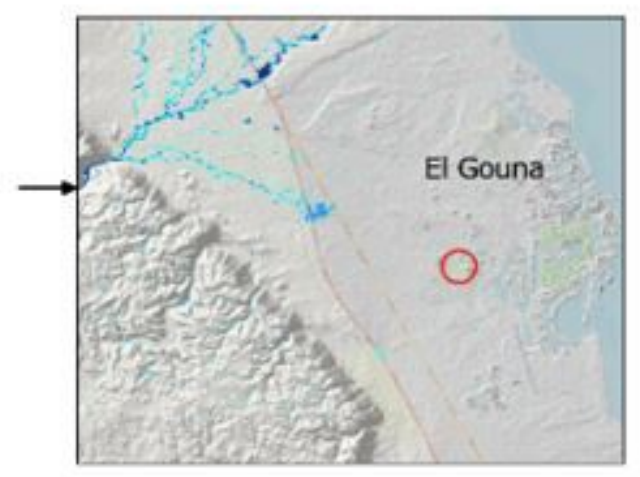

\section{Figure 12}

Water depth distributions in the model domain after 9 hours of simulation time considering different values for Infiltration and friction parameteters. Zc : crust thickness, Kc: hydraulic conductivity of crust, Kclay: hydraulic conductivity for clay after Rawls et al. [54], see Table 1, n: Manning's friction coefficient (background map: @OpenStreetMap contributors) 


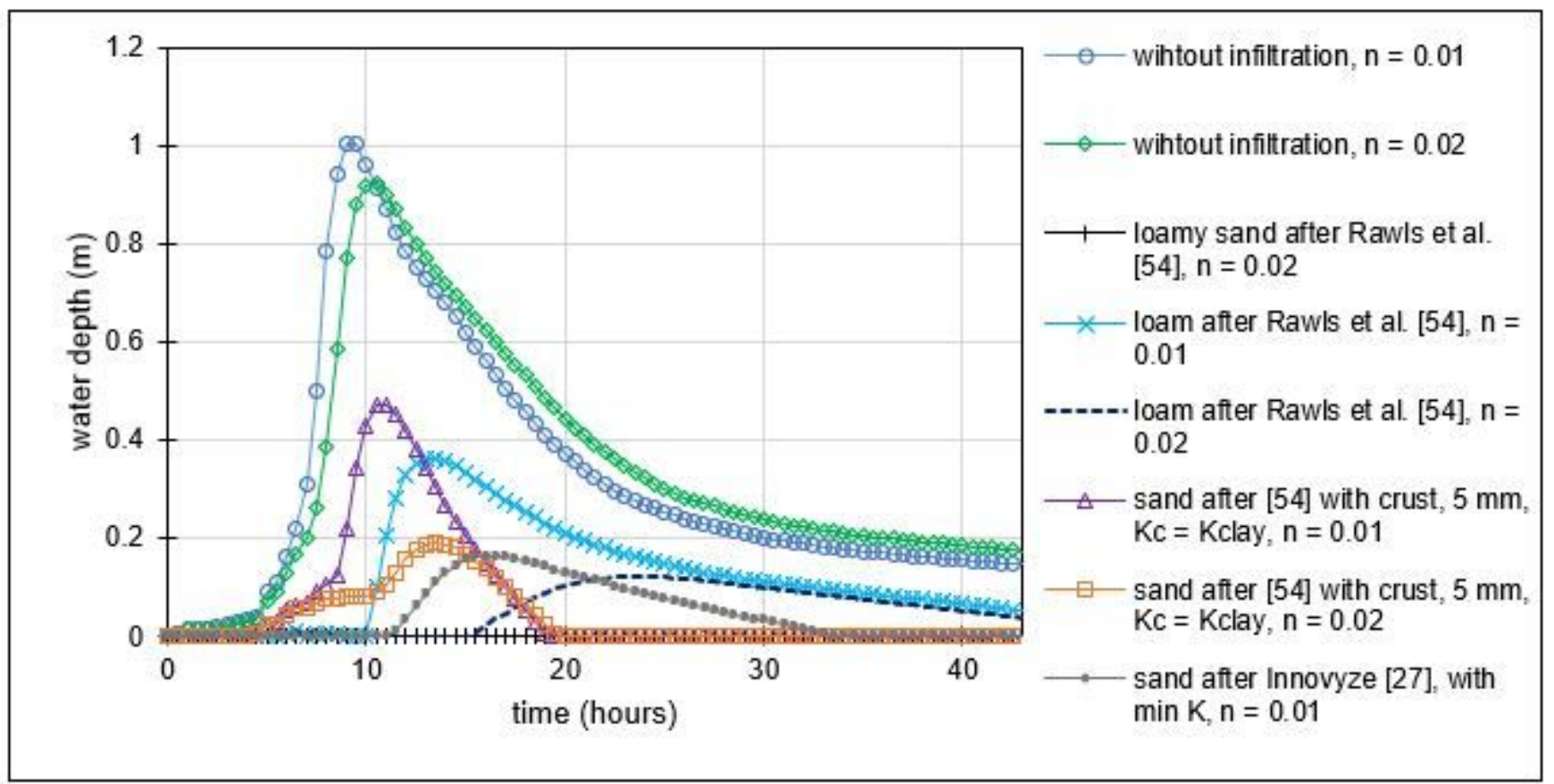

\section{Figure 13}

Temporal development of simulated water depths at location of maximum water depth indicated with a red circle in Fig. 12, considering different infiltration settings and values of Manning's friction coefficient. $\mathrm{K}$ : hydraulic conductivity, Kc: hydraulic conductivity of crust, $\mathrm{n}$ : Manning's friction coefficient in sm-1/3 


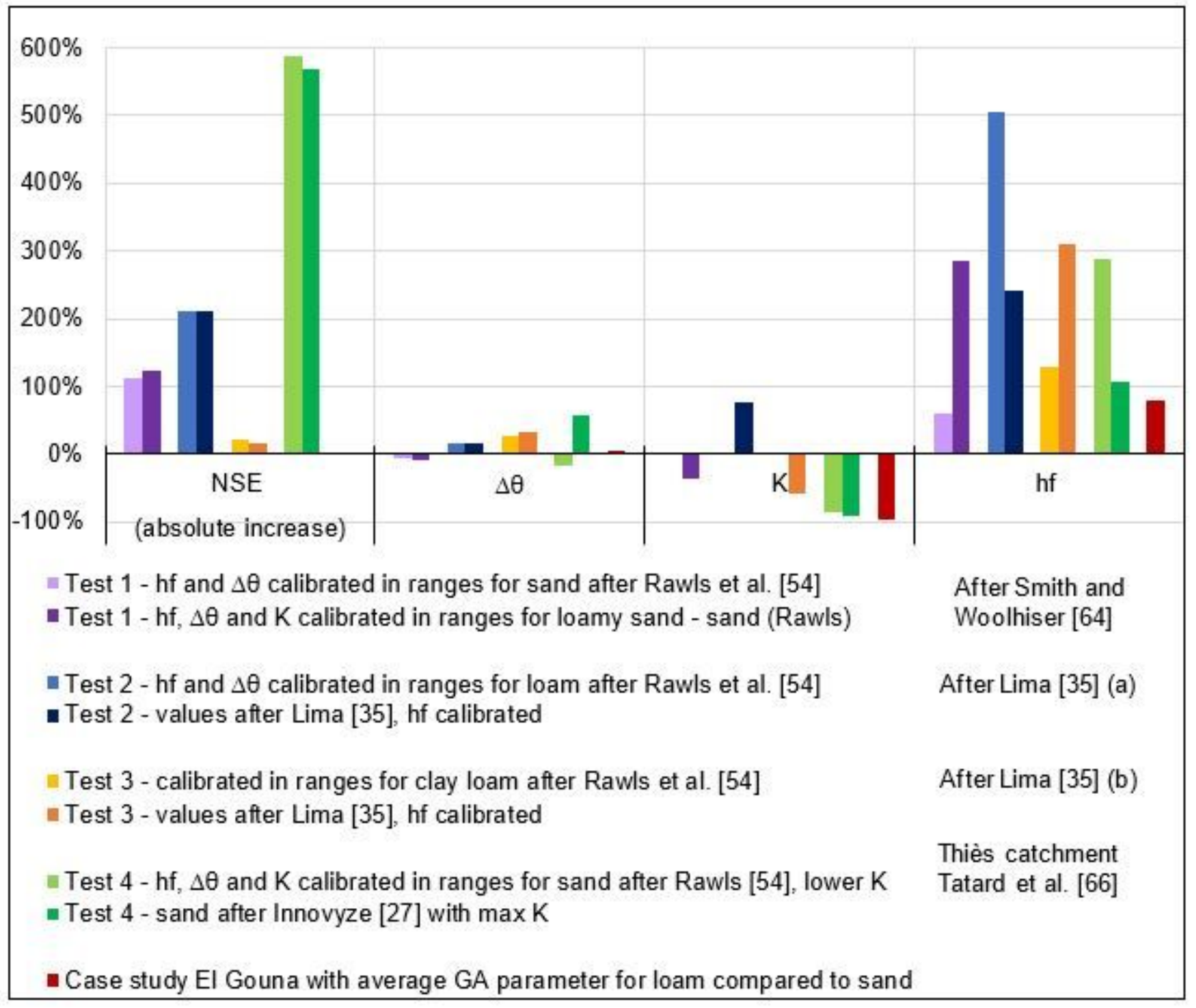

\section{Figure 14}

Percental changes of the Green-Ampt (GA) parameters for each test case compared to the average values after Rawls et al. [54]. NSE: Nash-Sutcliffe efficiency, $\Delta \theta$ : initial soil moisture deficit, K: hydraulic conductivity, hf: capillary suction head and wetted front, n: Manning's friction coefficient, max K: maximum hydraulic conductivity after Innovyze [27] according to Akan [2] (see Table 2) 